\title{
Localised strain in fissured clays: the combined effect of fissure orientation and confining pressure
}

\author{
Erika Tudisco ${ }^{1}$ (1) $\cdot$ Claudia Vitone $^{2}$ (D) $\cdot$ Cristina Mondello $^{2}$ (1) $\cdot$ Gioacchino Viggiani $^{3}$ (I) $\cdot$ Stefanos Athanasopoulos $^{4} \cdot$ \\ Stephen A. Hall ${ }^{4,5}$ [ $\cdot$ Federica Cotecchia ${ }^{2}$
}

Received: 23 October 2020 / Accepted: 5 August 2021 / Published online: 24 August 2021

(c) The Author(s) 2021

\begin{abstract}
This paper reports the main results of an experimental study on the mechanics of intensely fissured natural clays, extending our previous studies on scaly clay from Santa Croce di Magliano. While previous work focused on the influence of the orientation of fissures with respect to the loading direction, the present investigation specifically explores an additional, important variable: the stress level. The combined effect of fissure orientation and confining pressure was studied by setting up a large campaign of plane strain compression experiments, in which different combinations of these two variables were tested. Conventional global stress-strain measurements were complemented by measuring displacement and strain fields through two-dimensional digital image correlation. Such rich information provided a clear and consistent picture of the interplay between fissure orientation and stress level and revealed complex deformation patterns, which cannot be ignored for a proper interpretation of the material response.
\end{abstract}

Keywords Confining pressure $\cdot$ Digital image correlation (DIC) $\cdot$ Fissure inclination $\cdot$ Fissured clay $\cdot$ Localised deformation · Plane strain

\section{Introduction}

Fissured clays are widespread in chain areas, due to tectonism, and are often the source of severe geotechnical engineering problems (e.g. [8]). Their mechanical behaviour has been thoroughly studied in the laboratory since the early 70 s (e.g. $[10,11]$ —also see the many references quoted by $[12,15])$ to reveal significant complexity. The

Erika Tudisco

erika.tudisco@construction.lth.se

Claudia Vitone

claudia.vitone@poliba.it

1 Division of Geotechnical Engineering - LTH, Lund University, Lund, Sweden

2 DICATECh, Politecnico di Bari, Bari, Italy

3 Univ. Grenoble Alpes, CNRS, Grenoble INP, 3SR, F-38000 Grenoble, France

4 Division of Solid Mechanics - LTH, Lund University, Lund, Sweden

5 Lund Institute of Advanced Neutron and X-ray Science (LINXS), Lund, Sweden shear strength strongly depends on the level of fissuring (often referred to as fissuring intensity), as well as the orientation of the fissures with respect to the loading direction. This has been investigated in a series of experimental studies (e.g. $[16,18,20]$ ) for different natural clays including the intensely fissured clay of Santa Croce di Magliano, from the Southern Italian Apennines. In a previous study [15], we made use of the reductionist approach to deduce some basic, general aspects of the influence of fissuring on the global behaviour of clay. This was done by taking into account the variable composition and physical properties of the studied soils, plus structural discontinuities resulting from in situ strain localisation due to tension or shear stresses generated by tectonic, erosion and weathering processes [7]. Based on a large number of plane strain compression tests and measurements linking global and local behaviour, the main conclusion from these previous studies (see sketch in Fig. 1) was that when the fissures are oriented normal to the major principal stress, the deformation processes in fissured clays are essentially similar to those observed in intact clays (Fig. 1a). On the contrary, when fissures are parallel or inclined at about $45^{\circ}$ 


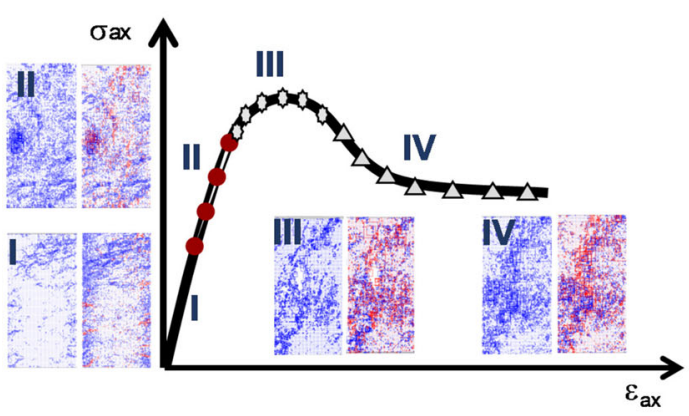

(a) Continuum behaviour: horizontal fissures

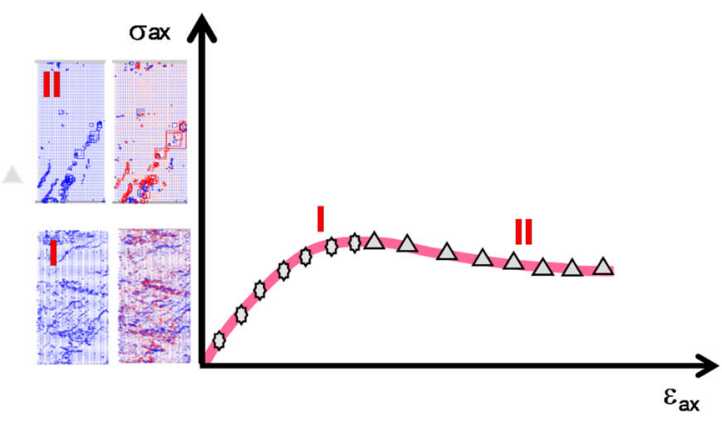

(b) Discrete behaviour: medium inclined and vertical fissures

Fig. 1 Sketch of main findings from our previous studies on intensely fissured clay from Santa Croce di Magliano, showing global stress-strain behaviour and DIC-derived strain fields (deviatoric on the left and volumetric on the right) for a horizontal fissures (continuum behaviour) and b medium inclined and vertical fissures (discrete behaviour) (adapted from [17])

to the loading direction, pre-existing fissures are activated early in deviatoric loading, and the main failure mechanism is axial splitting or sliding, respectively. In fact, in these studies, the sample deformation consisted essentially of almost rigid body motion between a discrete number of solid blocks from the beginning of the test up to the eventual "failure" of the sample [16, 20]-see Fig. $1 \mathrm{~b}$. However, the above findings were all obtained in the absence of lateral confinement, i.e. all tests were run at zero confining pressure. The experimental campaign reported herein represents a significant step forward in that the tests are conducted with confining pressure. This allowed the investigation of the combined effect of fissure orientation and confining pressure on the process of strain localization in plane strain compression. As in our previous studies, conventional global stress-strain measurements were systematically complemented by measuring displacement and strain fields through two-dimensional digital image correlation (2D-DIC).

\section{Material tested}

The tested clay comes from Santa Croce di Magliano (SCM, hereafter) in the Italian southern Apennines. It belongs to an Oligocene-Miocene Flysch succession of red and green clays and calcareous strata. Due to the strong tectonism, the material has been subjected to large displacements and strain. Such complex history is reflected in a relatively high overconsolidation ratio $(\mathrm{OCR}=3.5)$, and-most importantly-an intense network of fissures which splits the clay into millimetre lens-shaped elements (the scales)-see Fig. 2. The fissuring intensity is the highest possible (I6: very high) in the F-ID chart proposed by [15], due to both the small average volume of the scales (about $0.15 \mathrm{~cm}^{3}$ ) and their very high specific surface (about $1000 \mathrm{~m}^{2} / \mathrm{m}^{3}$ ). At the scale of a laboratory specimen, there is mainly one single prevailing direction of the scales, which coincides with the orientation of the fissures (F1 in the F-ID chart). SCM clay is a silty clay of high plasticity, and it can be classified as $\mathrm{CH}$ according to the USCS [1]. $\mathrm{X}$-ray diffraction analyses confirm that the high activity of the SCM scaly clay results from large quantities of smectite and mixed illite-smectite layers (see Fig. 2).

The samples were extracted from an outcropping in the SCM territory at 3-6 m below ground level, after removal of a thick stratum of soil. C-shaped stainless steel samplers were designed specifically both to minimise the sampling disturbance and to be able to perform plane strain tests (which require prismatic specimens). The samplers were pushed directly into the soil soon after lubricating their inner surface with silicon oil to minimise friction [14]. As shown in Fig. 3, the clay was sampled with three different fissure inclinations. Each full sampler was then wrapped in cling film and waxed with paraffin on-site, in order to reduce water content losses when taking the sampler to the laboratory for testing.

\section{Experimental setup and data interpretation}

Due to the intense fissuring, the transfer of the material from the $\mathrm{C}$-shaped samplers into specimens to be tested was challenging. The first step was careful extrusion from the steel samplers followed by gentle trimming down to the size required for testing, and finally rectifying and smoothening the specimen surfaces. The prismatic specimens were nominally $20 \mathrm{~mm}$ thick, $60 \mathrm{~mm}$ high and 30 $\mathrm{mm}$ wide, corresponding to a slenderness ratio (i.e. the ratio of height to width) of 2 , as required by the loading device that was employed for the realisation of the experimental campaign: Lund University's Plane-strain Apparatus (LUPA) [4]. This specimen size is significantly larger 


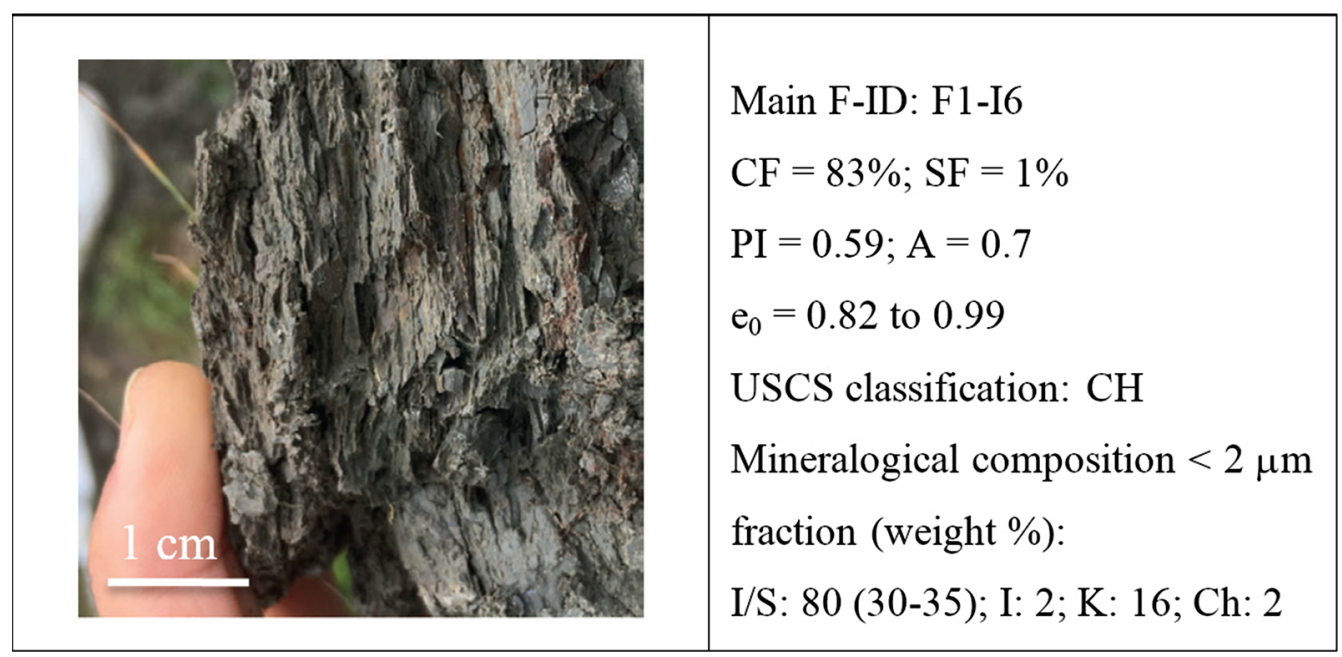

Fig. 2 SCM scaly clay: left: photograph of the material illustrating the scaly structure; right: F-IDs, physical and mineralogical properties. Key: $C F$ clay fraction, $S F$ sand fraction [2], PI plasticity index [3], $A$ activity index, $e_{0}$ initial void ratio, USCS unified soil classification system [1], I/ $S$ mixed-layers illite/smectite (illite $\%$ in brackets), $I$ illite, $K$ kaolinite, $C h$ chlorite-data [15]
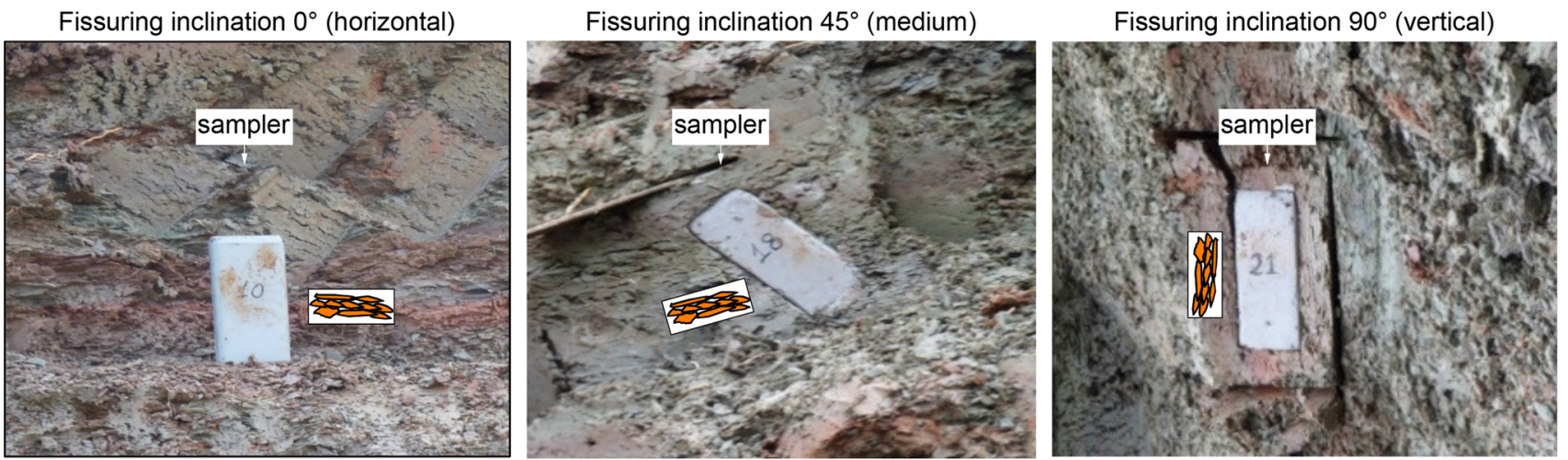

Fig. 3 In situ sampling of the scaly clays. Left: horizontal fissures; centre: medium-inclined fissures; right: vertical fissures

than the fissure spacing (about 8 times), which is enough to achieve the representative elementary volume size for the I6 clay $[5,15]$.

In the LUPA device, the specimen was mounted between two rigid plates, inducing plane deformation. Axial and lateral stresses were applied independently, corresponding to the major $\left(\sigma_{1}\right)$ and minor $\left(\sigma_{3}\right)$ principal stresses, respectively. In the following, $\sigma_{3}$ will be referred to as the confining pressure. The intermediate principal stress $\left(\sigma_{2}\right)$, which is orthogonal to the rigid plates, is not measured. The two plates are made by borosilicate glass to be rigid and allow the acquisition of photographs of the inplane specimen deformation throughout the tests. To minimise the effect of friction between the specimen and the two plates, without affecting the optical access to the specimen, the plates were lubricated with silicone grease. Further technical details concerning LUPA can be found in [4].
As shown in Fig. 4, the plane strain device is part of a bigger experimental setup that also consists of an image acquisition system, a pressure controller and a loading rig. The image acquisition system for the tests reported herein involved a single high-resolution (28.8 MPixel) CCD camera and a pair of light sources. To avoid overheating that would accelerate soil desaturation, the photographed surface of the specimens was illuminated using lightemitting diode (LED) sources, either single bulbs or arrays.

In each plane strain test, the shearing phase was preceded by an "isotropic" compression phase, by applying equal values to $\sigma_{1}$ (axial stress) and $\sigma_{3}$ (lateral stress). Note that this does not guarantee that the intermediate principal stress $\sigma_{2}$ is also equal to the other two (this only holds true for linear isotropic elasticity with $v=0.5$ ). The subsequent deviatoric loading was performed under displacement control, with an applied axial (vertical) upward displacement of the lower piston at a rate of $0.006 \mathrm{~mm} / \mathrm{min}$. Photographs were acquired every $30 \mathrm{~s}$ during the "isotropic" 


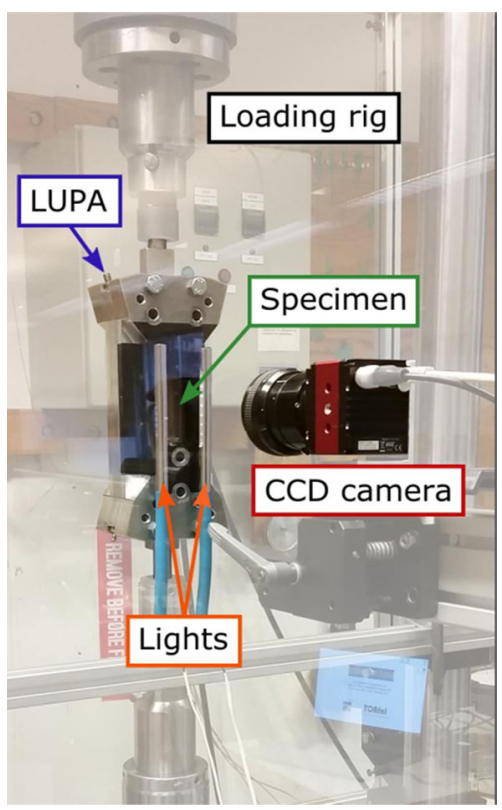

Fig. 4 Plane strain test apparatus

phase and every 20 min during shearing. They were analysed using 2D-DIC to follow the deformation processes throughout each test. The software TomoWarp2 was used for the 2D-DIC [13].

To increase the accuracy and precision of the DIC, the image texture was augmented by applying a 'speckle pattern' to the surfaces of the specimens. Speckle patterns are spots that, in this case, were sprayed using an aerosol spray-paint over the surface of the specimen. This speckletextured surface provided higher image contrast that could be easily identified in the acquired photographs at the scale of the measurement. The pixel size of the acquired images was $13 \mu \mathrm{m}$.

The DIC procedure is based upon finding the optimal displacements to map small images, subsets, centred on nodal points distributed over the whole image. Strains were computed from the local gradient of the displacements within the nodal grid. These strain tensors are most efficiently visualized in terms of volumetric and maximum shear strains, which are calculated as $\operatorname{det}(\mathbf{F})-1$, where $\mathbf{F}$ is the deformation gradient, and $\sqrt{\left(\frac{\varepsilon_{x}-\varepsilon_{y}}{2}\right)^{2}+\varepsilon_{x y}^{2}}$, respectively.

The DIC approach used herein is a piece-wise continuum analysis, i.e. continuity is assumed within each subset [20] and no strong discontinuities (i.e. discontinuities of displacement) can be detected within a local subset. Furthermore, in the definition of strain, any discontinuities between subsets will be interpreted as strain. However, for SCM scaly clay, the deformation processes often consist of relative displacements along pre-existing fissures. Therefore, whilst DIC provides a correct analysis of the displacement and strain of blocks around the developing fissures, deformation cannot always be properly described in terms of strain in the region of the fissures. This implies that strain values computed across fissures should be considered as smeared representations of displacement discontinuities.

\section{Testing programme}

Plane strain compression tests were performed under three confining pressures (i.e. 50, 300 and $600 \mathrm{kPa}$ ) without any re-saturation or consolidation of the specimen prior to loading. The initial values of void ratio varied between 0.820 and 0.990 (Fig. 2). While the clay scales were fully saturated, the specimens' saturation was below $100 \%(\mathrm{Sr}=$ $72-86 \%$ ), mainly due to the presence of open fissures. See also [19] for further details about the initial state of SCM scaly clay. Table 1 summarises the experimental programme, which consisted of a total of 15 tests, including the actual specimen dimensions, the inclination of the preexisting fissures, the confining pressure, a sketch of the fissured specimens at the end of the tests (thick lines are used for the main shear bands formed during shearing), and the measured inclinations of the main shear bands.

Each test is identified by a label that includes letters and numbers according to the following logic: the first letter indicates the fissure inclination to the horizontal $(\mathrm{V}$ for vertical: $90^{\circ}$; I for inclined: $45^{\circ}-50^{\circ}$; $\mathrm{H}$ for horizontal: $0^{\circ}$ ); the first number is needed because more than one test was performed with the same fissure inclination; the second and last number, after the hyphen, defines the confining pressure in $\mathrm{kPa}$. For example, label V2-50 indicates the second test on a specimen with vertical fissures tested under $50 \mathrm{kPa}$ confining pressure. For comparison, Table 1 also includes three additional tests that were performed by [20] on the same scaly clay, but without confinement (tests V1-0, I1-0 and $\mathrm{H} 1-0)$.

For the sake of space, results from a selection of the tests will be shown in the following, which have been chosen as representative of the influence of fissures inclination and confining pressure on both the global stress-strain behaviour and the mechanisms of localised deformation observed.

\section{Results}

\subsection{DIC-derived strain fields}

Results of DIC analyses carried out during the nine selected plane strain tests are shown in Figs. 5, 6, 7, 8, 9, $10,11,12$ and 13 . The sequence numbers of the photographs used in the analysis are noted on the force- 
Table 1 List of the plane strain compression tests performed in the present study

\begin{tabular}{|c|c|c|c|c|c|}
\hline \multirow{2}{*}{ Test label } & $\begin{array}{l}\text { Specimen } \\
\text { dimentions }\end{array}$ & \multirow{2}{*}{$\begin{array}{c}\text { Fissure } \\
\text { inclination to } \\
\text { the horizontal }\end{array}$} & $\begin{array}{c}\text { Confining } \\
\text { pressure }\end{array}$ & \multirow{2}{*}{$\begin{array}{l}\text { Sketch of the } \\
\text { specimen at the } \\
\text { end of the test }\end{array}$} & $\begin{array}{l}\text { Inclination of the main shear } \\
\text { band to the orizontal }\end{array}$ \\
\hline & $(\mathrm{mm})$ & & (kPa) & & $\left({ }^{\circ}\right)$ \\
\hline V1-0* & $80.0-40.0-35.0$ & \multirow{6}{*}{ Vertical } & 0 & & 90 \\
\hline V2-50 & $61.0-31.0-20.0$ & & 50 & & 53 \\
\hline V3-50 & $60.0-30.0-20.0$ & & 50 & & 55 \\
\hline V4-300 & $60.0-30.0-20.0$ & & 300 & & 66 \\
\hline V5-600 & $59.0-31.0-20.0$ & & 600 & & 68 \\
\hline V6-600 & $61.0-30.4-20.0$ & & 600 & & 55 \\
\hline I1-0* & $82.2-40.2-35.0$ & \multirow{5}{*}{ Medium } & 0 & & 56 \\
\hline I2-50 & $58.0-30.0-20.0$ & & 50 & & 50 \\
\hline I3-50 & $60.0-30.0-20.0$ & & 50 & & 43 \\
\hline I4-300 & $60.0-30.0-20.0$ & & 300 & & 35 \\
\hline I5-600 & $60.0-30.0-20.0$ & & 600 & & 55 \\
\hline $\mathrm{H} 1-0 *$ & $150.0-70.0-35.0$ & \multirow{7}{*}{ Horizontal } & 0 & & 40 \\
\hline $\mathrm{H} 2-50$ & $60.0-30.0-20.0$ & & 50 & & 57 \\
\hline $\mathrm{H} 3-50$ & $61.7-31.1-20.0$ & & 50 & & 45 and 20 \\
\hline $\mathrm{H} 4-300^{* *}$ & $60.0-30.0-20.0$ & & 300 & & 45 and 34 \\
\hline H5-300 & $59.0-30.0-20.0$ & & 300 & & 52 \\
\hline H6-600 & $60.0-30.0-20.0$ & & 600 & & 46 \\
\hline $\mathrm{H} 7-600$ & $60.0-30.0-20.0$ & & 600 & & 48 \\
\hline
\end{tabular}

*Tests performed by [20]

**In this test, because of excessively irregular shape of the specimen, out-of-plane deformation took place 


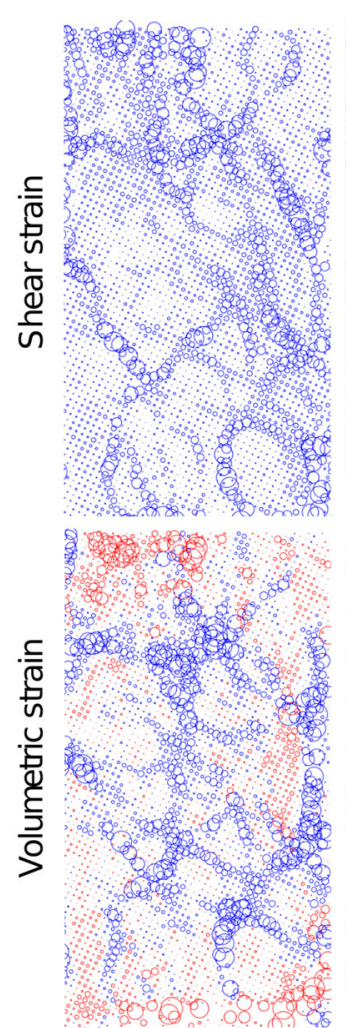

62-65
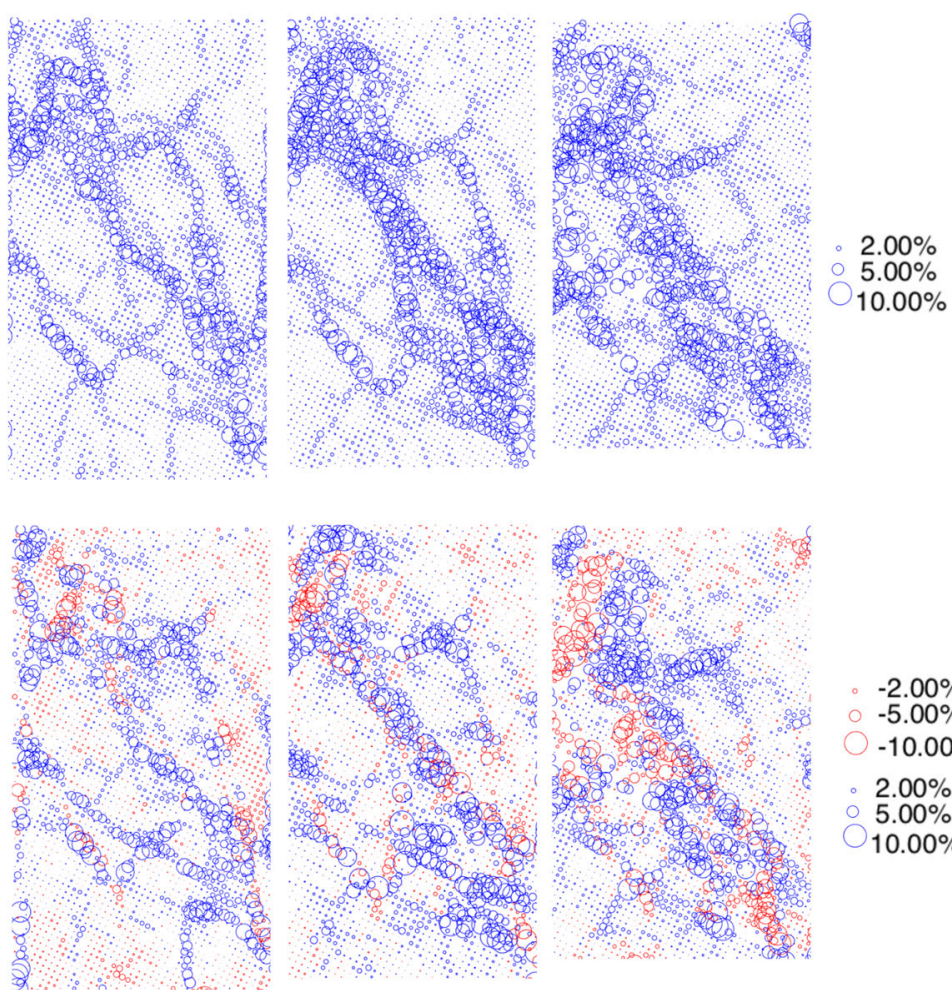

65-70

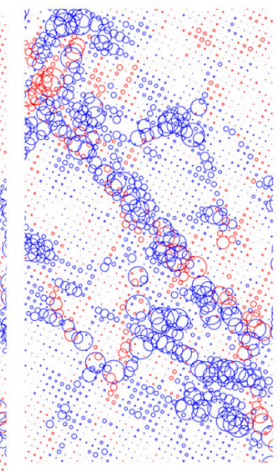

75-80

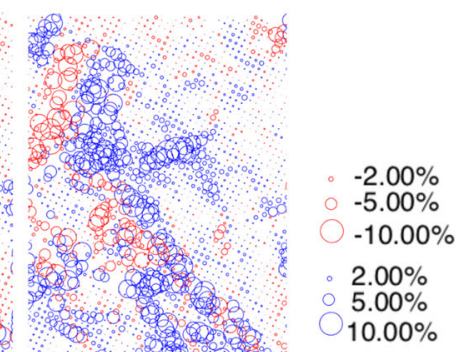

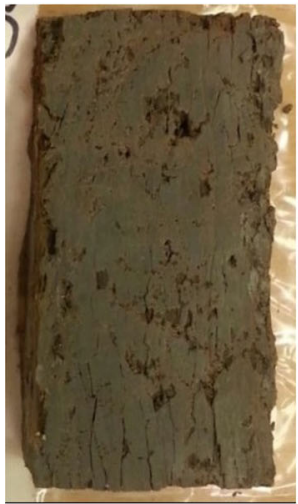

Before the test

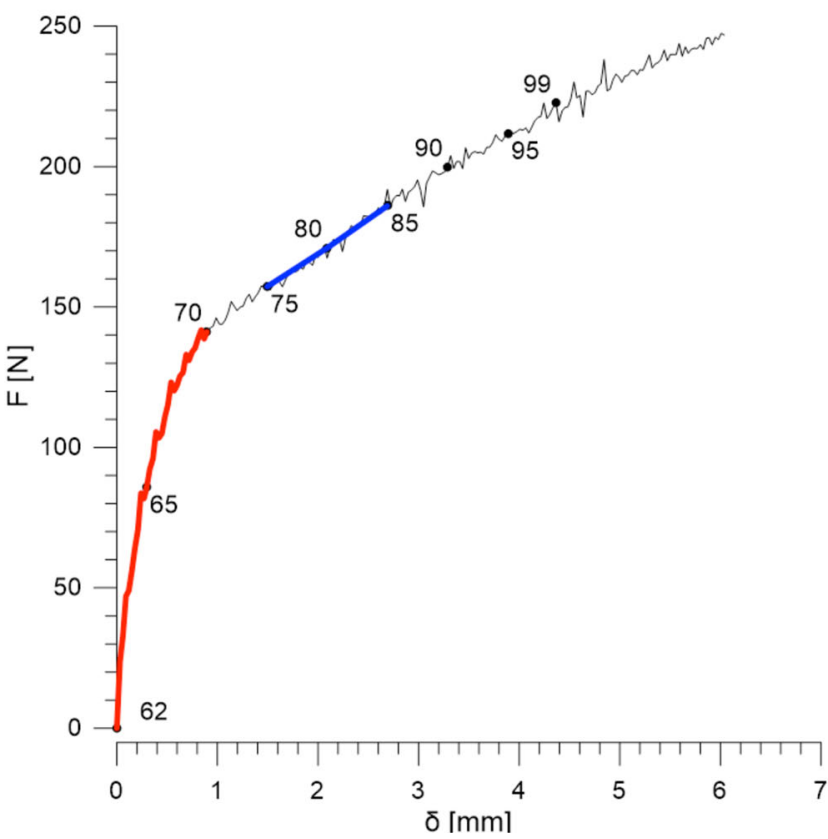

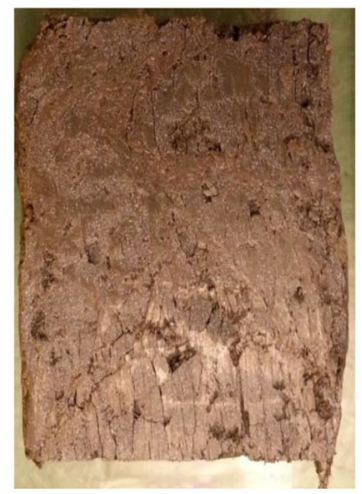

After the test

Fig. 5 Test V3-50. Load-displacement curve and DIC-derived shear and volumetric strain fields for selected load increments (in blue and red along the curve). The load increments in red correspond to the onset of strain localisation. The two photographs show the clay specimen before and at the end of the test (colour figure online)

displacement curves, which are shown for each test together with pictures of each specimen at the beginning and at the end of the test. The following discussion will make reference to the selected strain increments highlighted by thick lines on the force-displacement curves in the figures. The figures also show maps of the magnitudes of the maximum shear strain, $\varepsilon_{\mathrm{s}}$, in the top row, and volumetric strain, $\varepsilon_{\mathrm{v}}$, in the bottom row, for each investigated 


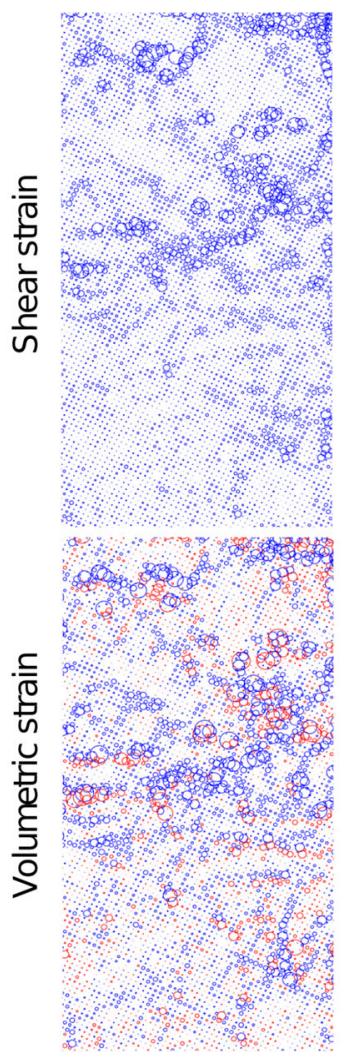

75-80
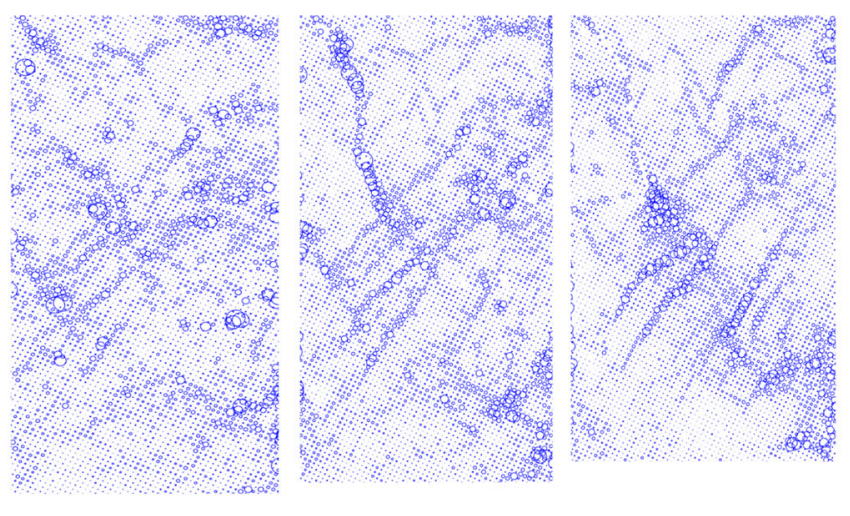

$2.00 \%$

$5.00 \%$

$10.00 \%$

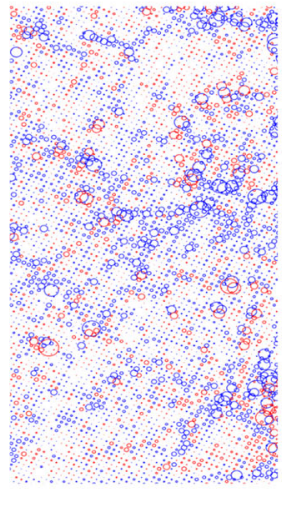

110-115

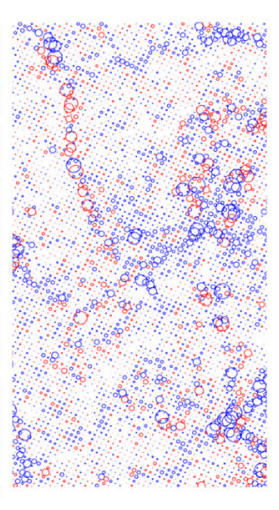

140-145

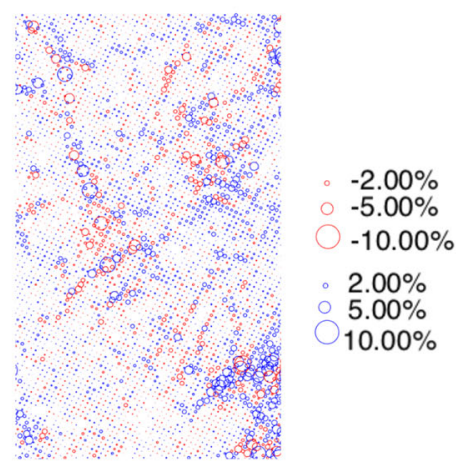

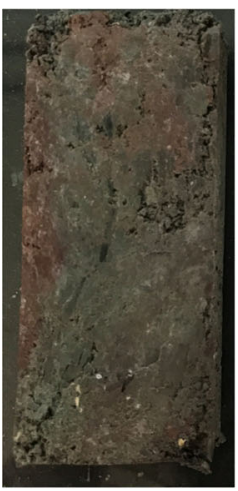

Before the test

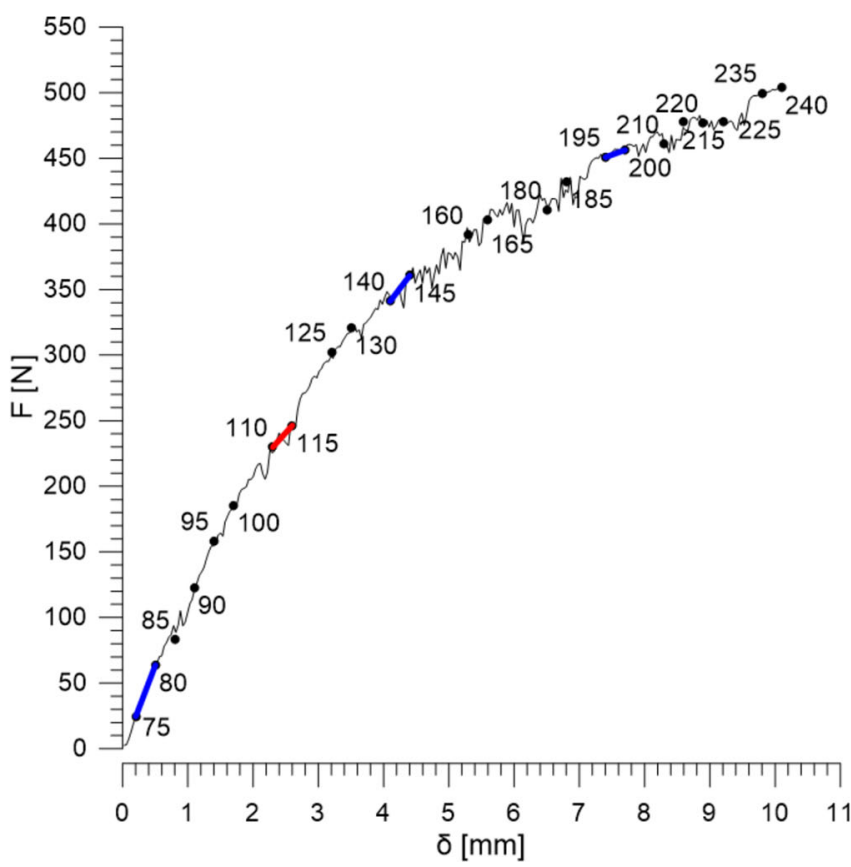

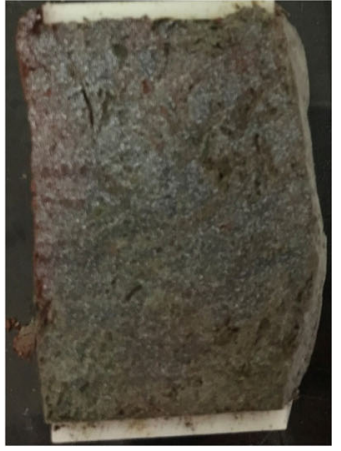

After the test

Fig. 6 Test V4-300. Load-displacement curve and DIC-derived shear and volumetric strain fields for selected load increments (in blue and red along the curve). The load increments in red correspond to the onset of strain localisation. The two photographs show the clay specimen before and at the end of the test (colour figure online) 

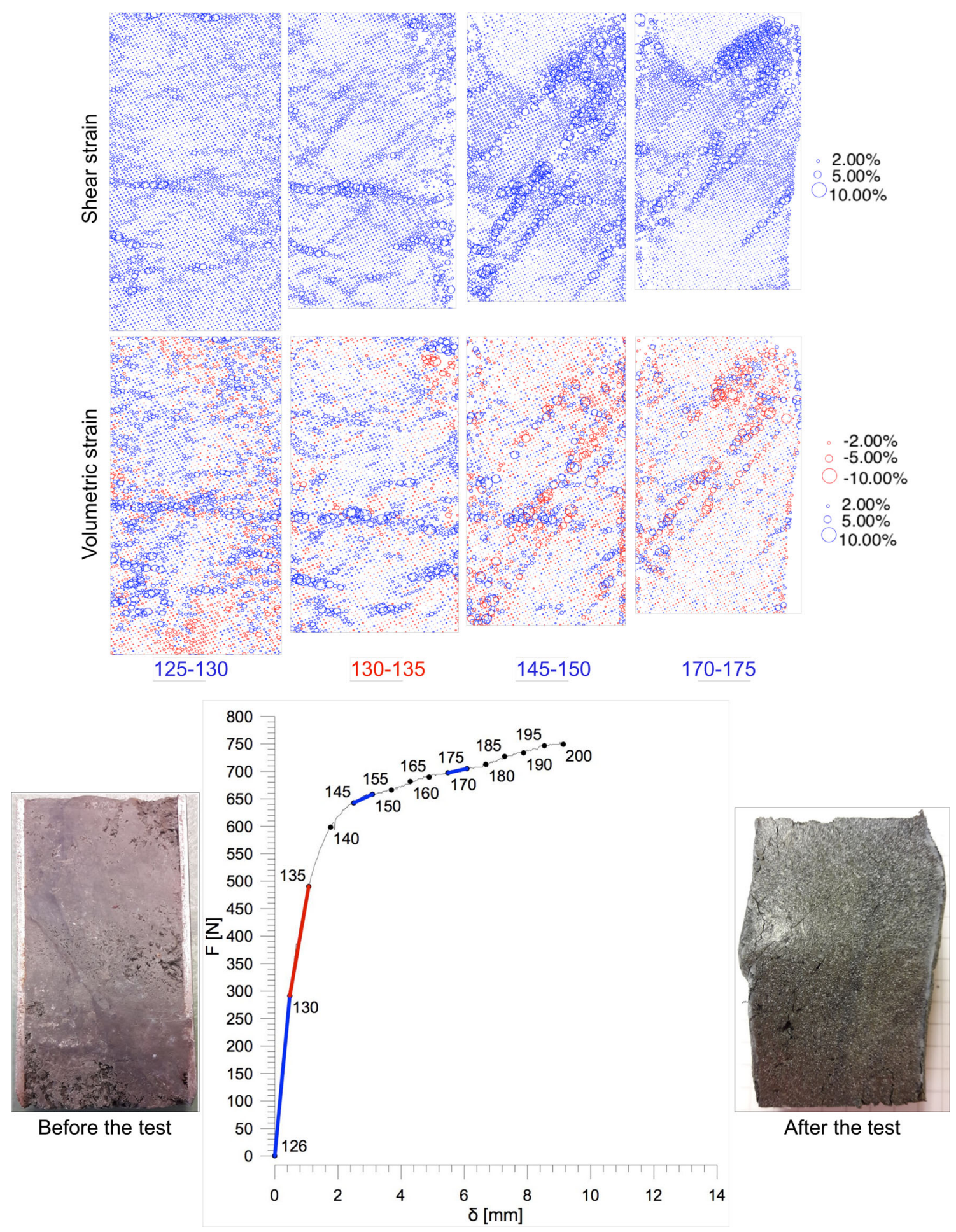

Fig. 7 Test V6-600. Load-displacement curve and DIC-derived shear and volumetric strain fields for selected load increments (in blue and red along the curve). The load increments in red correspond to the onset of strain localisation. The two photographs show the clay specimen before and at the end of the test (colour figure online)

increment as derived by 2D-DIC. The numbers of the strain increments showing the onset of localisation are indicated in red in the figures. The size of the circle symbols in these maps is proportional to the value of the relevant strain quantity. For volumetric strain, red symbols refer to dilation and blue symbols to contraction. 

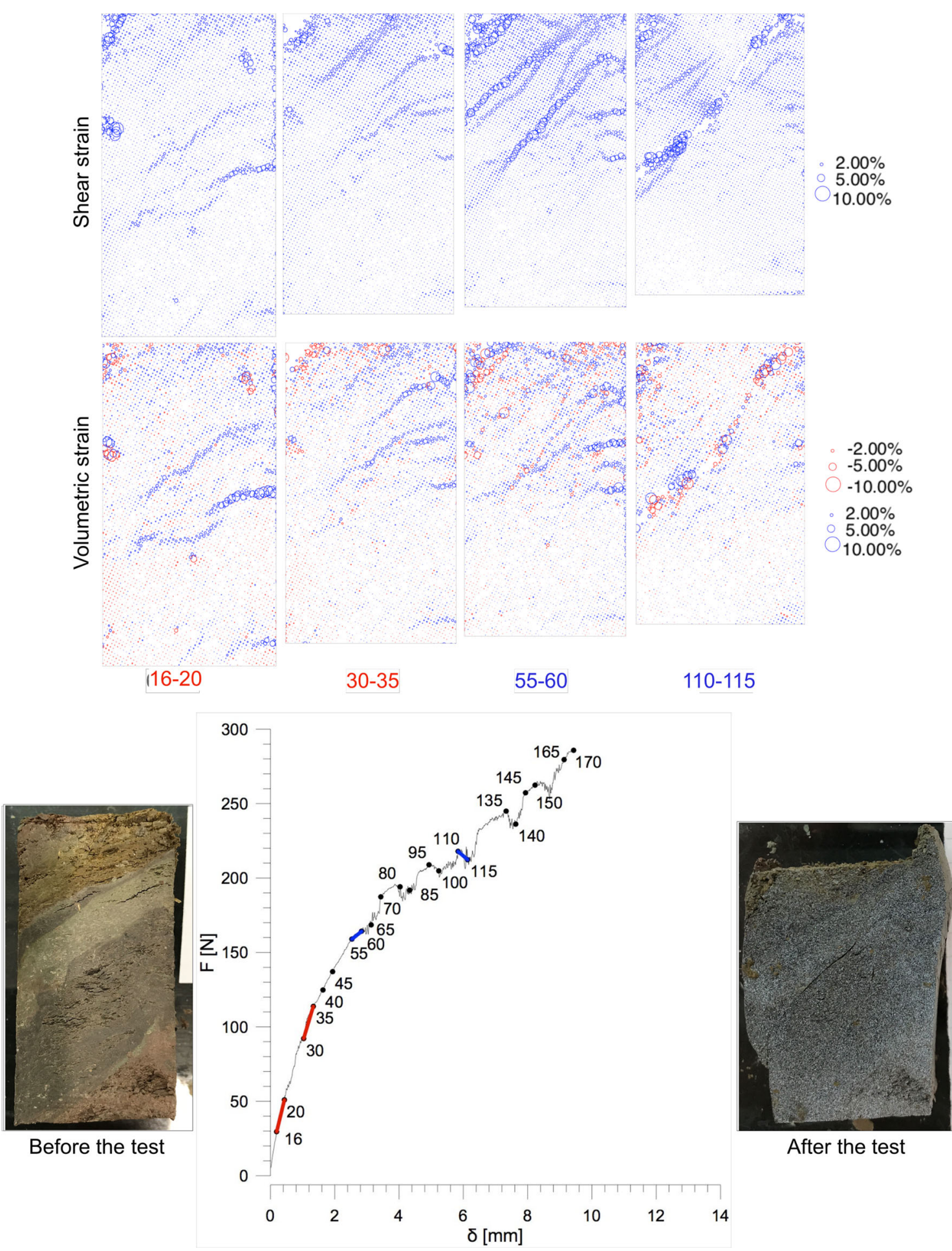

Fig. 8 Test I2-50. Load-displacement curve and DIC-derived shear and volumetric strain fields for selected load increments (in blue and red along the curve). The load increments in red correspond to the onset of strain localisation. The two photographs show the clay specimen before and at the end of the test (colour figure online)

\subsubsection{Vertical fissures}

Figure 5 shows the evolution of the strain fields during test V3-50 (recall this means $50 \mathrm{kPa}$ confining pressure and vertical fissures). The pattern of deformation is characterised-from the very beginning of the test—by the activation of multiple pre-existing sub-vertical fissures, underlying the regions of localised shear (and volumetric) 

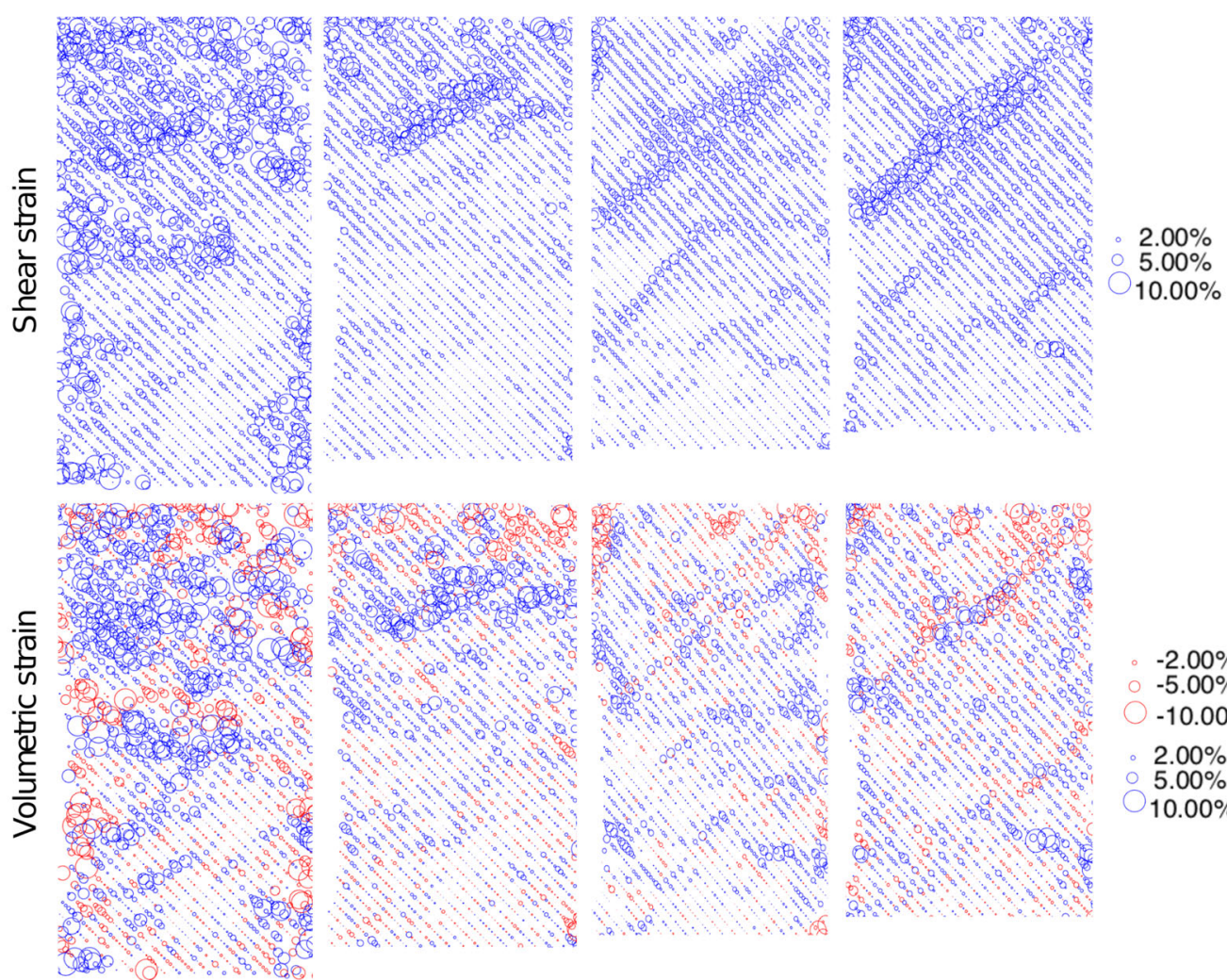

$$
\begin{aligned}
& -2.00 \% \\
& -5.00 \% \\
& -10.00 \% \\
& 2.00 \% \\
& 5.00 \% \\
& 10.00 \%
\end{aligned}
$$

198-205

210-215

240-245

255-260

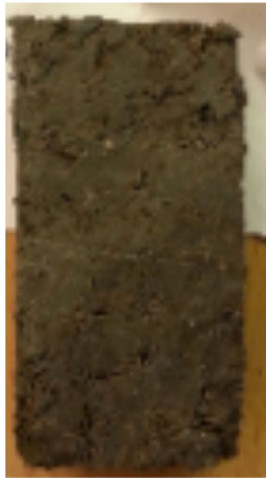

Before the test

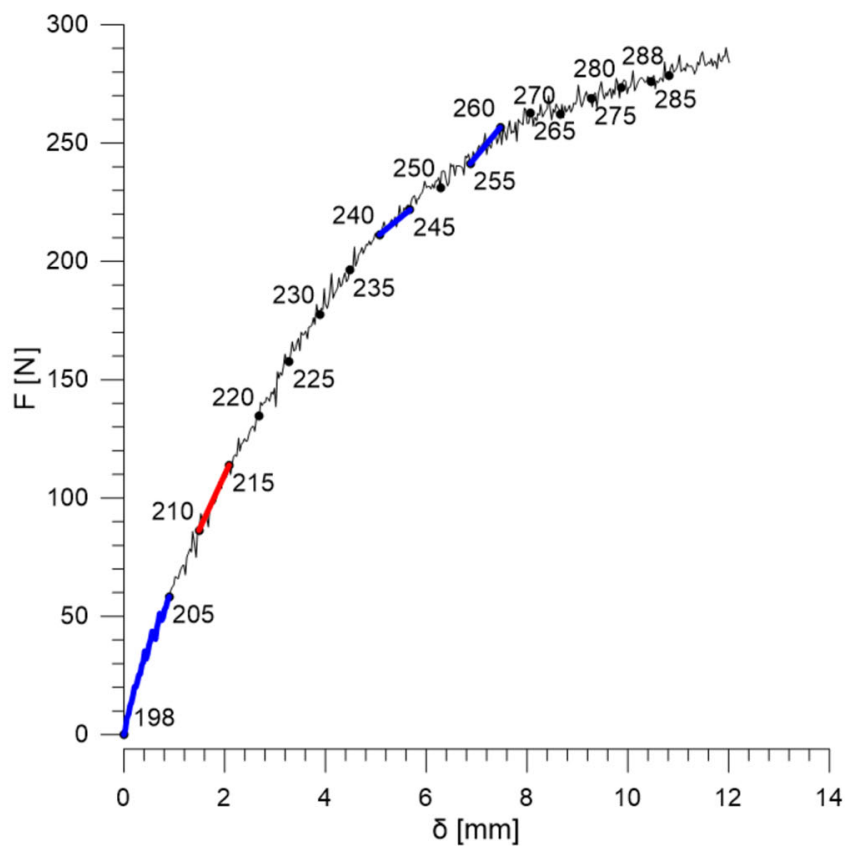

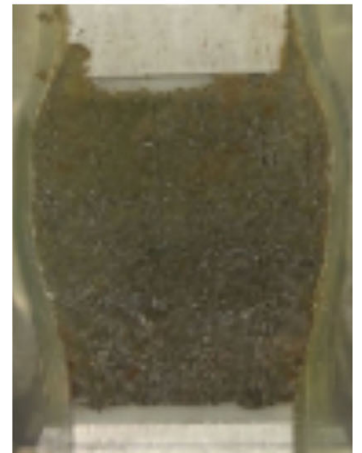

After the test

Fig. 9 Test I4-300. Load-displacement curve and DIC-derived shear and volumetric strain fields for selected load increments (in blue and red along the curve). The load increments in red correspond to the onset of strain localisation. The two photographs show the clay specimen before and at the end of the test (colour figure online)

strain. The coalescence of these fissures starts in the middle of the specimen and gives rise to a few shear bands-the main one of which crosses the specimen almost entirely by increment $65-70$ (0.7 $\mathrm{mm}$ axial displacement). Fissure sliding appears to be always accompanied by fissure opening or closing. The clay blocks in between the fissures 


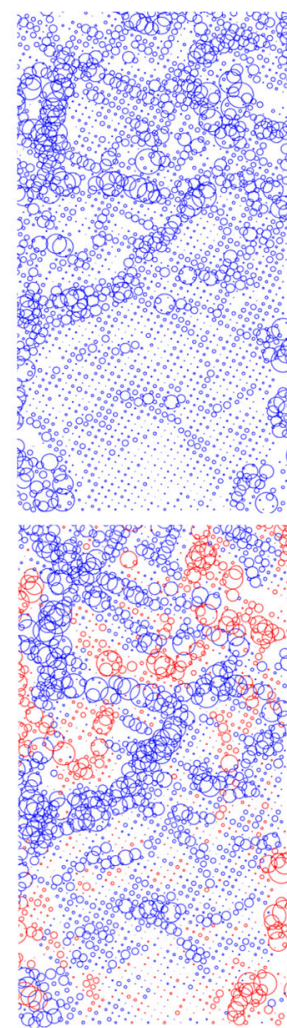

$192-200$
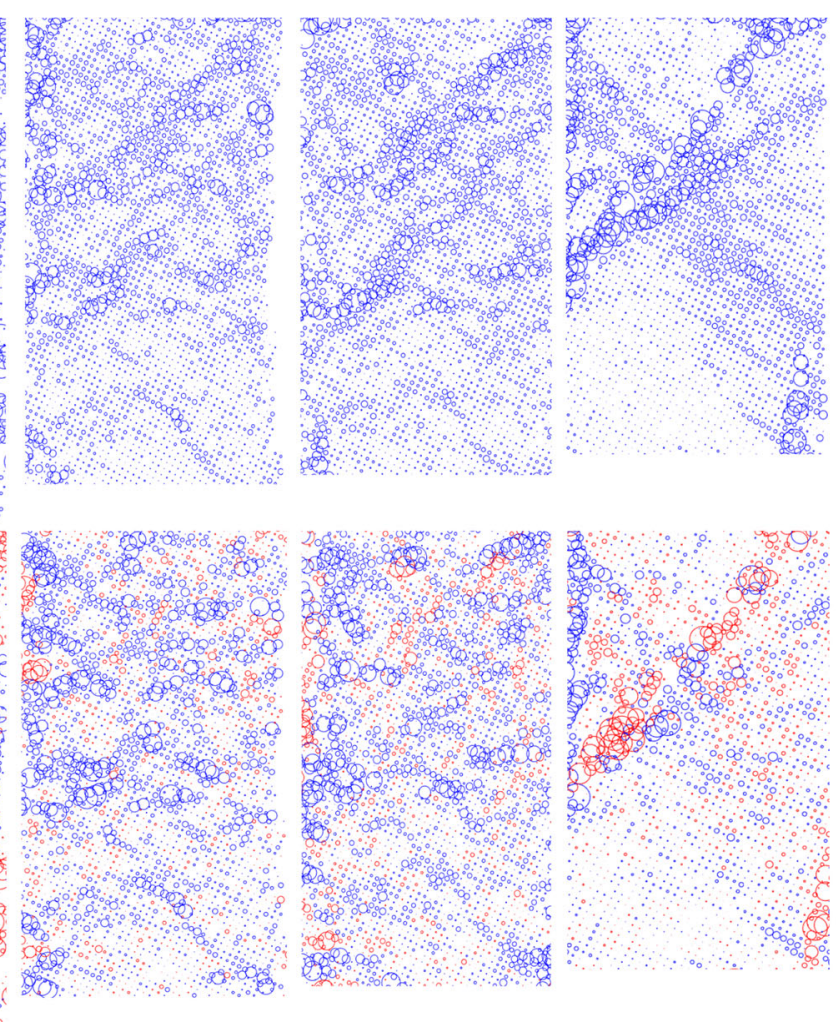

$205-210$

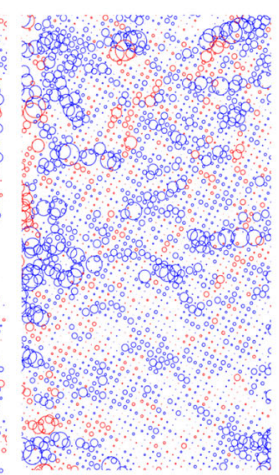

$215-220$

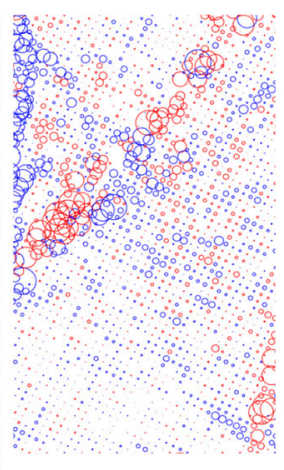

$285-290$

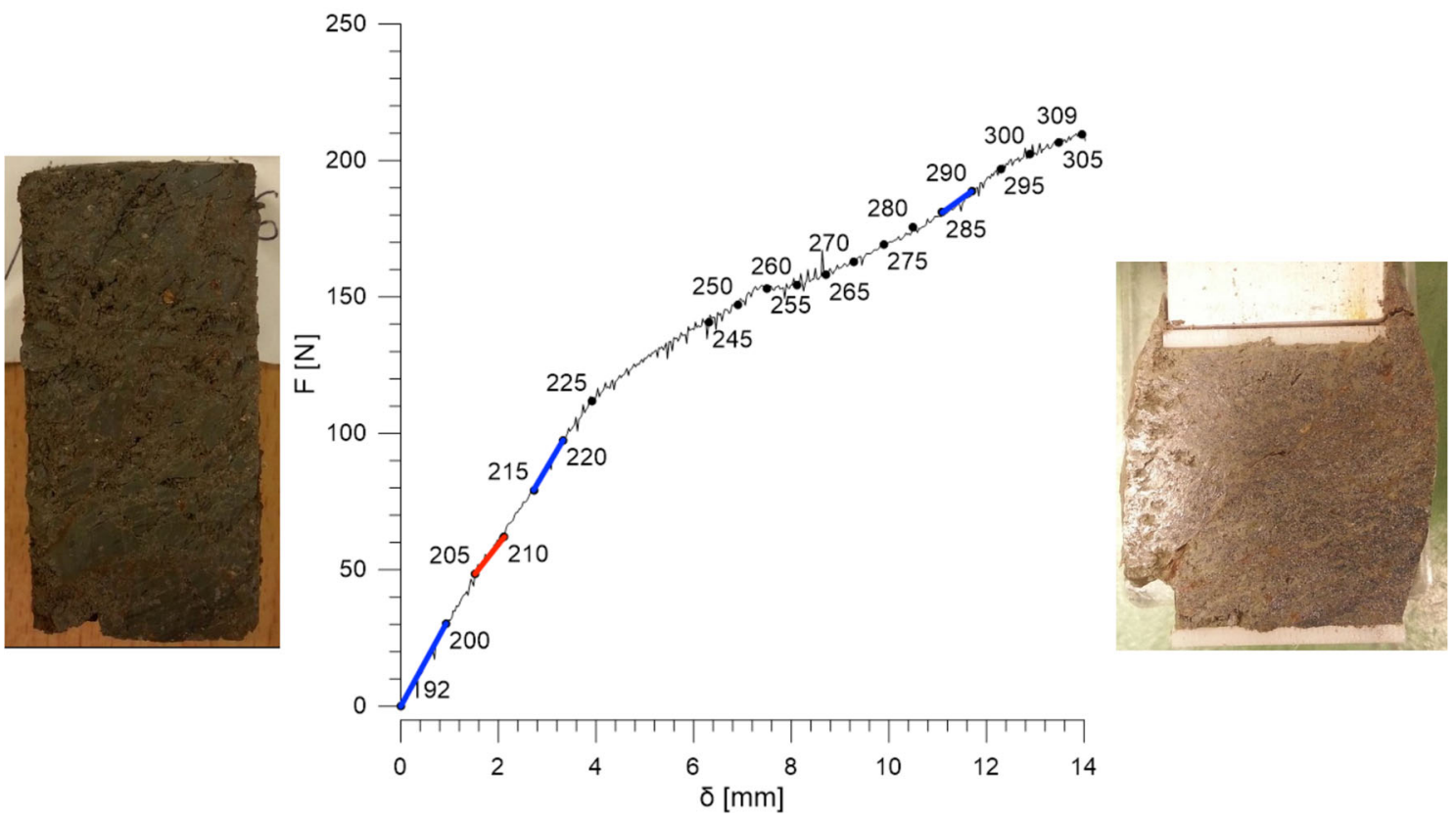

Fig. 10 Test I5-600. Load-displacement curve and DIC-derived shear and volumetric strain fields for selected load increments (in blue and red along the curve). The load increments in red correspond to the onset of strain localisation. The two photographs show the clay specimen before and at the end of the test (colour figure online)

remain essentially undeformed throughout the process. The final failure mode, visible to the naked eye on the specimen at the end of the test, consists of sliding along a shear band inclined at about $53^{\circ}$ to the horizontal.
Figure 6 shows the results from test V4-300. During increment 75-80, the specimen deformed quite homogeneously. Only a few regions in the upper portion of the specimen exhibit volumetric contraction, which 


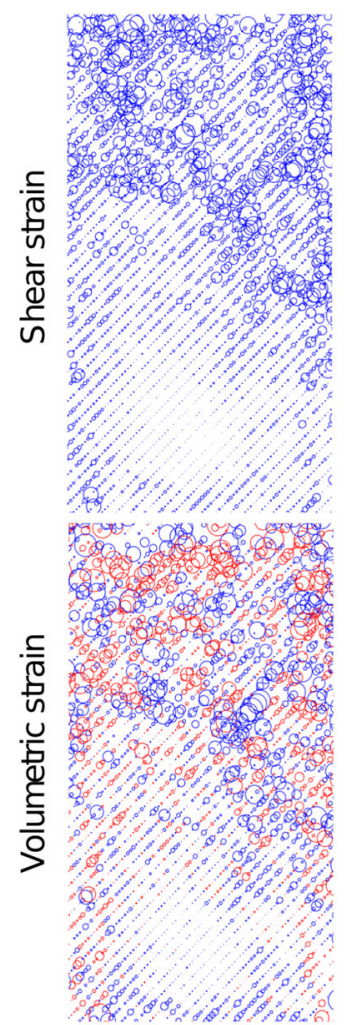

6-12

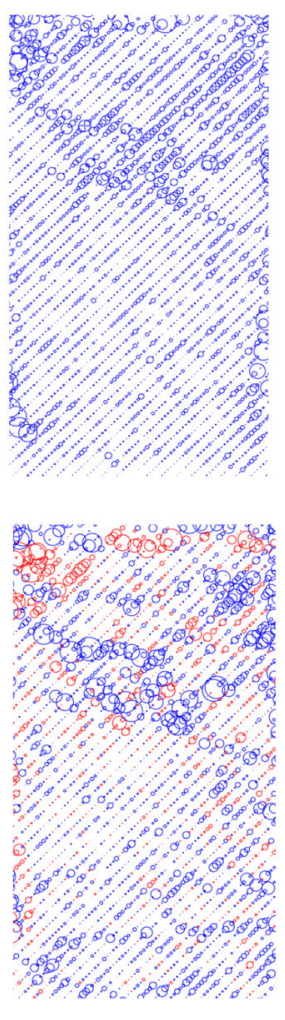

22-27
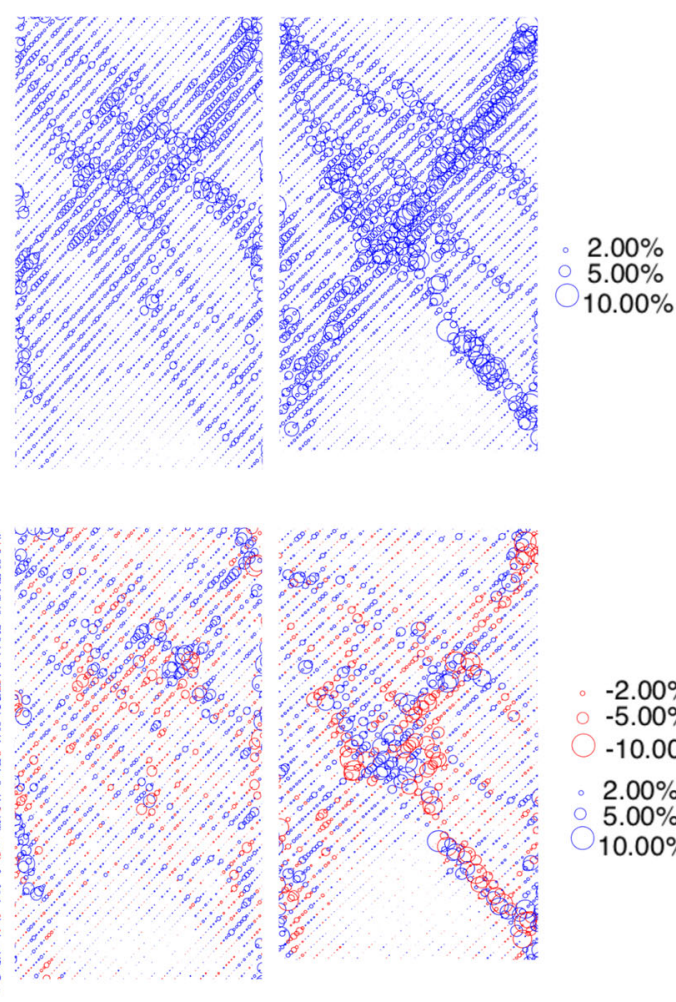

$-2.00 \%$
$-5.00 \%$

$-10.00 \%$

$2.00 \%$

$5.00 \%$

$10.00 \%$

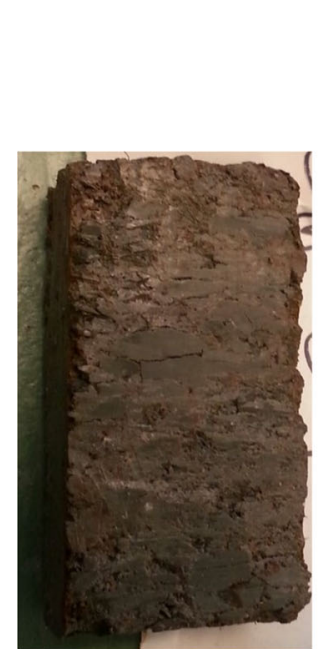

Before the test

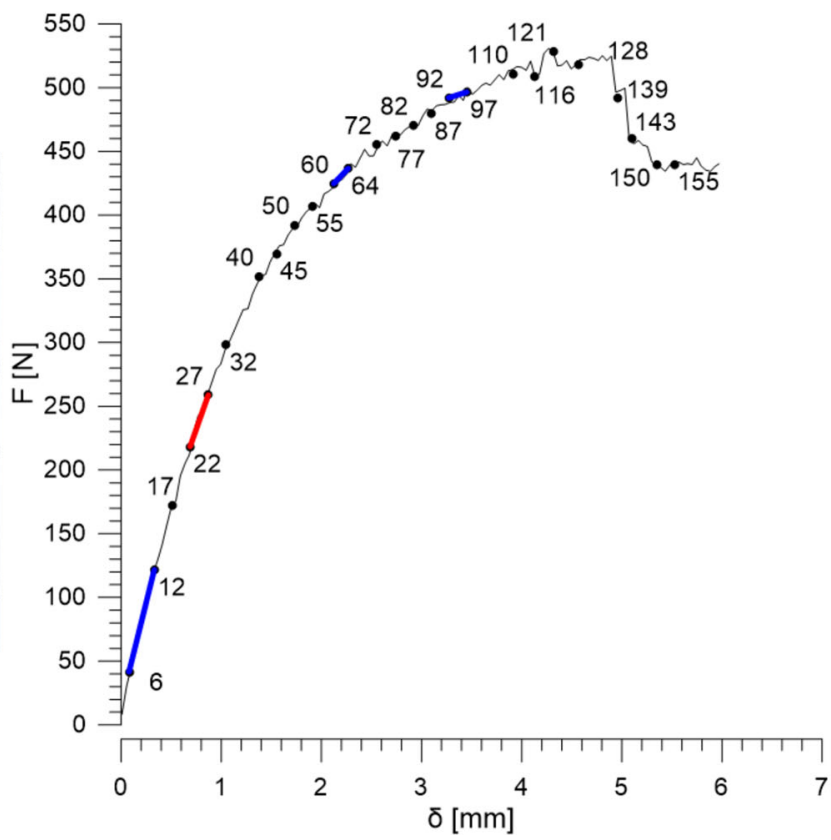

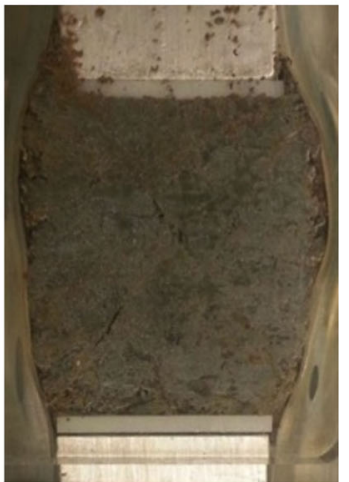

After the test

Fig. 11 Test H2-50. Load-displacement curve and DIC-derived shear and volumetric strain fields for selected load increments (in blue and red along the curve). The load increments in red correspond to the onset of strain localisation. The two photographs show the clay specimen before and at the end of the test (colour figure online)

corresponds to closure of fissures. The same regions experience higher shear strains than the rest of the specimen, which indicates that compaction between the scales is accompanied by their relative adjustment and sliding. At the same time, slight episodes of volume increase (i.e. fissure opening) occur in the same regions of the specimen. In increment 110-115, a few shear bands become visible in the specimen, which further develop in the subsequent 


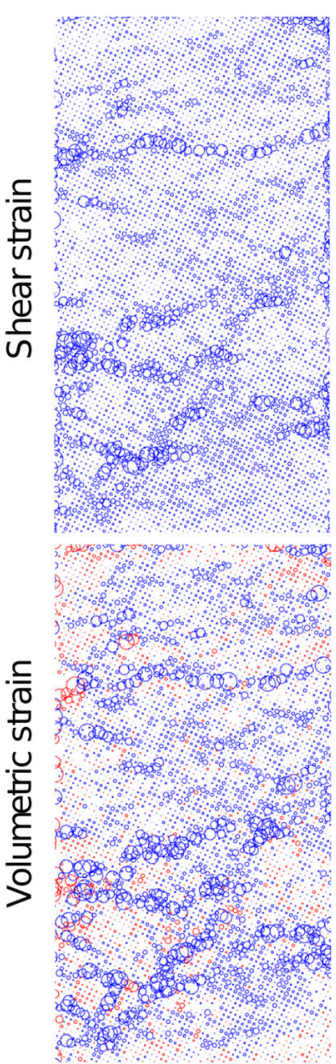

65-70
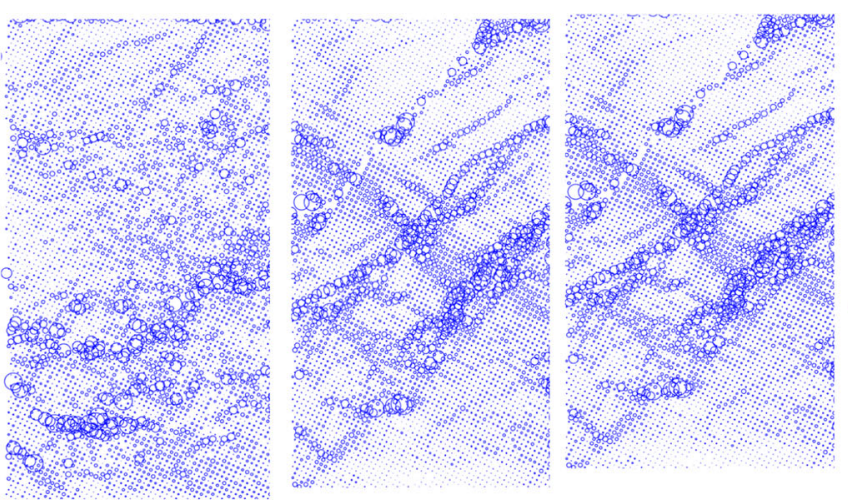

\section{$2.00 \%$}

$5.00 \%$

$10.00 \%$

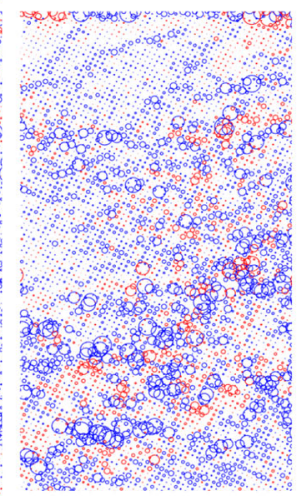

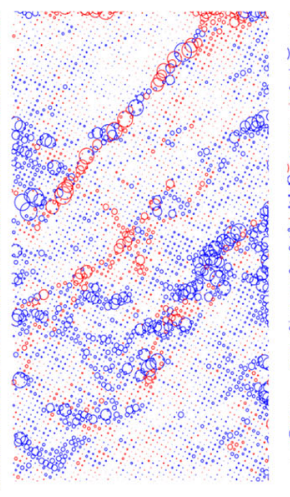

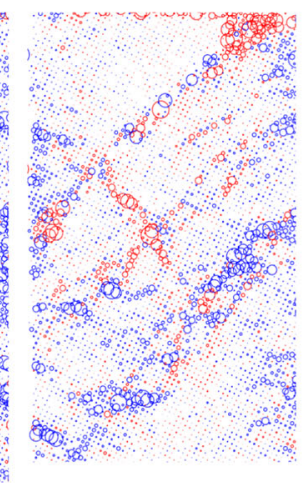

- $-2.00 \%$

$-5.00 \%$

$-10.00 \%$

$2.00 \%$

$5.00 \%$

$10.00 \%$

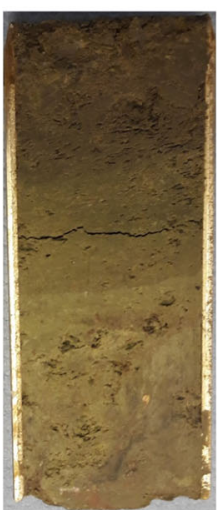

Before the test

75-80

100-105

110-115

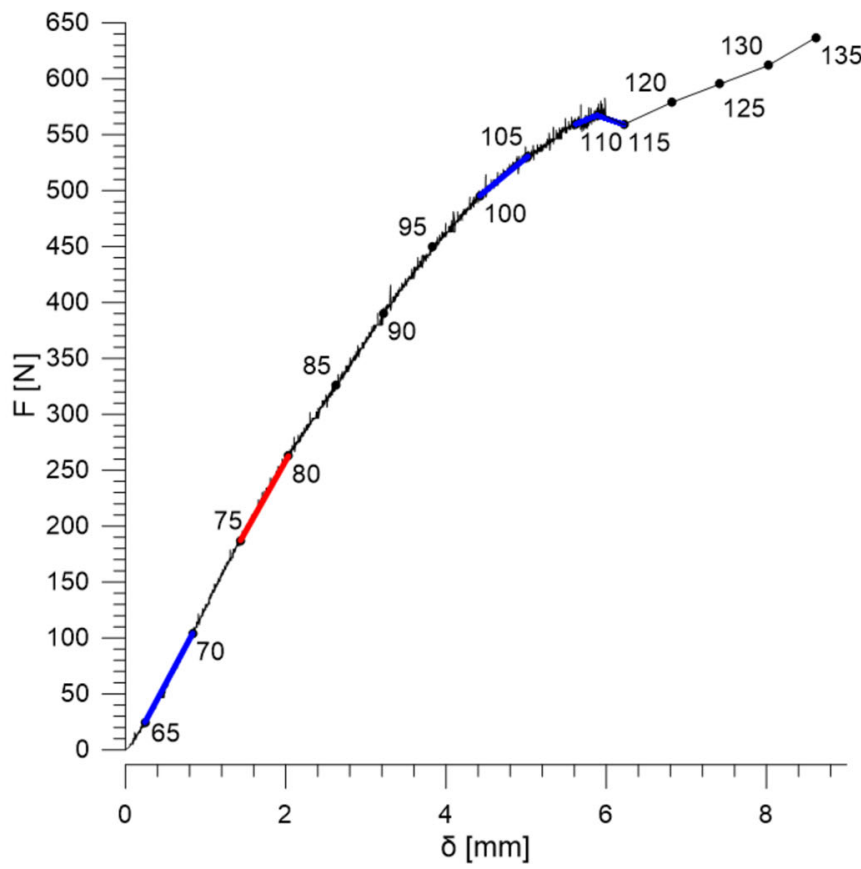

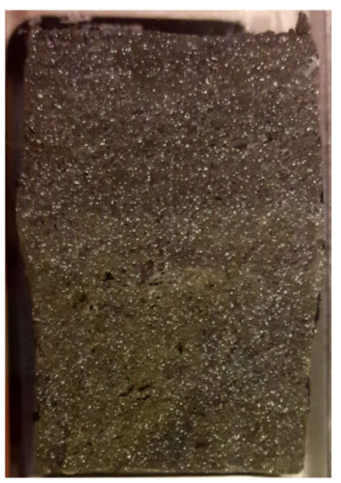

After the test

Fig. 12 Test H5-300. Load-displacement curve and DIC-derived shear and volumetric strain fields for selected load increments (in blue and red along the curve). The load increments in red correspond to the onset of strain localisation. The two photographs show the clay specimen before and at the end of the test (colour figure online) 

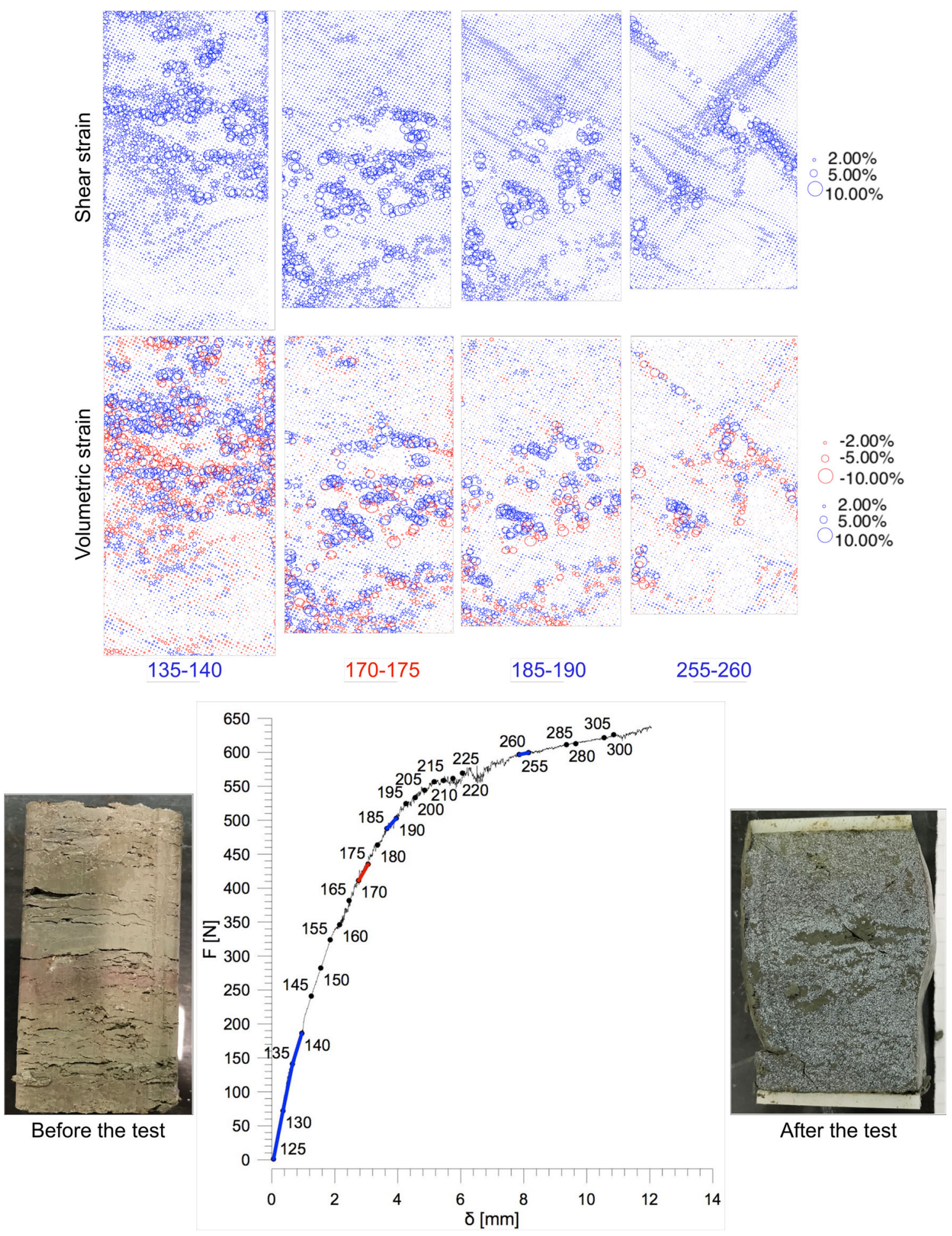

Fig. 13 Test H6-600. Load-displacement curve and DIC-derived shear and volumetric strain fields for selected load increments (in blue and red along the curve). The load increments in red correspond to the onset of strain localisation. The two photographs show the clay specimen before and at the end of the test (colour figure online)

increments. At the end of the test, a main shear band is possibly visible across the whole specimen (from top left to bottom right), which is accompanied by several secondary crossing bands, not completely formed.
Figure 7 shows the results from test V6-600. The evolution of the strain fields during the test is quite similar to that observed in test V4-300: the deformation is initially relatively homogeneous, and then, a few shear bands 
become increasingly visible in the specimen. At the end of the test, one main shear band possibly extends across the whole specimen (from top right to bottom left).

\subsubsection{Medium-inclined fissures}

In Fig. 8, the results of test I2-50 are shown. As observed for test V3-50, already early in the test (16-20) the pattern of deformation is characterised by the activation of multiple pre-existing medium-inclined fissures. These regions of localised shear and volumetric strain further develop in the following increments (30-35 and 55-60). Fissure sliding generally appears to be accompanied by fissure closing. The clay blocks in between the fissures remain essentially undeformed throughout the process. The final failure mode (see increment 110-115) consists of sliding along one (or possibly two) main shear bands inclined at about $50^{\circ}$ to the horizontal.

Figure 9 shows the results of test I4-300. At the beginning of the test (increment 198-205), differently from test I2-50, the specimen deformed quite uniformly, except for some compaction at the top of the specimen. A few parallel zones of localised deformation formed in the upper portion of the specimen in increment 210-215, likely corresponding to the activation of pre-existing fissures, inclined at about $45^{\circ}$ to the horizontal. They further extend at increment 240-245 and another medium-inclined shear band appeared in the centre of the specimen. Over increment 255-260, the behaviour consisted, essentially, of relative sliding between nearly rigid blocks. The photograph taken at the end of the test shows the main fissure crossing the specimen from its top right to the left.

The results of test I5-600 are reported in Fig. 10. The deformation process is quite similar to that of test I4-300: after initial homogeneous deformation, since increment 205-210, a well-defined pattern of localised deformation, inclined of $55^{\circ}$ to the horizontal, becomes visible. As for specimen I4-300, relative sliding is associated with compaction regions (fissure closing). The following increment reported in the figure (215-220) shows that two almost parallel shear bands formed. Again, later in the test (increment 285-290), the process consists essentially of relative sliding of nearly rigid blocks along one principal inclined shear band crossing the specimen. This is also confirmed by the visual inspection of the specimen at the end of the test.

\subsubsection{Horizontal fissures}

At the beginning of test H2-50 (Fig. 11), fairly homogeneous shear strain and fissure opening can be seen in the upper portion of the specimen. Starting from increment 22 27 , a shear strain localised region is visible at the top of the specimen. At this stage, volumetric compaction of horizontal fissures is also visible at the top and at the bottom of the specimen. In increment 60-64, conjugate shear bands appear in the upper part. In increment 92-97, the two shear bands extend towards the bottom of the specimen and cross it entirely forming an $\mathrm{x}$-shape failure mode (with inclination about $57^{\circ}$ to the horizontal). The same regions experience negative volume strains (dilation), which indicates that opening between the scales is complemented by their relative adjustment and sliding.

In test H5-300 (Fig. 12), the first increment (65-70) shows relatively homogeneous strain throughout the specimen, with diffuse compaction. The onset of localisation is visible in the bottom of the specimen in increment $75-80$ when a shear band appears, inclined at about $52^{\circ}$ to the horizontal. In increment $100-105$, this band becomes more persistent and pronounced. Two more bands, almost parallel to the first one, also become visible, along with another band in the conjugate direction. All these shear bands become more defined in increment 110-115. At this stage, the failure mechanism consists of relative sliding and opening processes between nearly rigid blocks.

In test H6-600 (Fig. 13), increment 135-140 shows relatively homogeneous strain throughout the specimen, with diffuse compaction-although the lower part of the specimen does not deform as much as the upper portion. The onset of localisation is possibly visible in the top left of the specimen in increment $170-175$ when a shear band appears, inclined of about $46^{\circ}$ to the horizontal. This band is more visible in increment $185-190$, along with another band, conjugate to the first one. These two conjugate bands remain active until the end of the test, see increment 255-260 and the photograph of the specimen after the test.

\subsection{Global behaviour}

Figure 14 shows the range of global stress-strain responses obtained in this study where the (nominal) axial stress is computed as the ratio of axial force $\mathrm{F}$ to the current cross section A (test H4-300 is missing because, in this case, outof-plane deformation took place). In all the tests, the DIC has indicated that localised deformation occurs in the specimen. In the presence of such localised deformation, it is clear that the meaning of stress and strain derived from boundary measurements of loads and displacements is only nominal, or conventional. Therefore, these curves should be interpreted as an overall response of the specimen and not as the constitutive response of the material.

Figure 14 indicates that, irrespective of the confining pressure, specimens with medium-inclined fissures (Fig. 14b) are weaker than those with either horizontal or vertical fissures (Fig. 14a, c, respectively). At zero or low $(50 \mathrm{kPa})$ confinement, the stress-strain response of the 


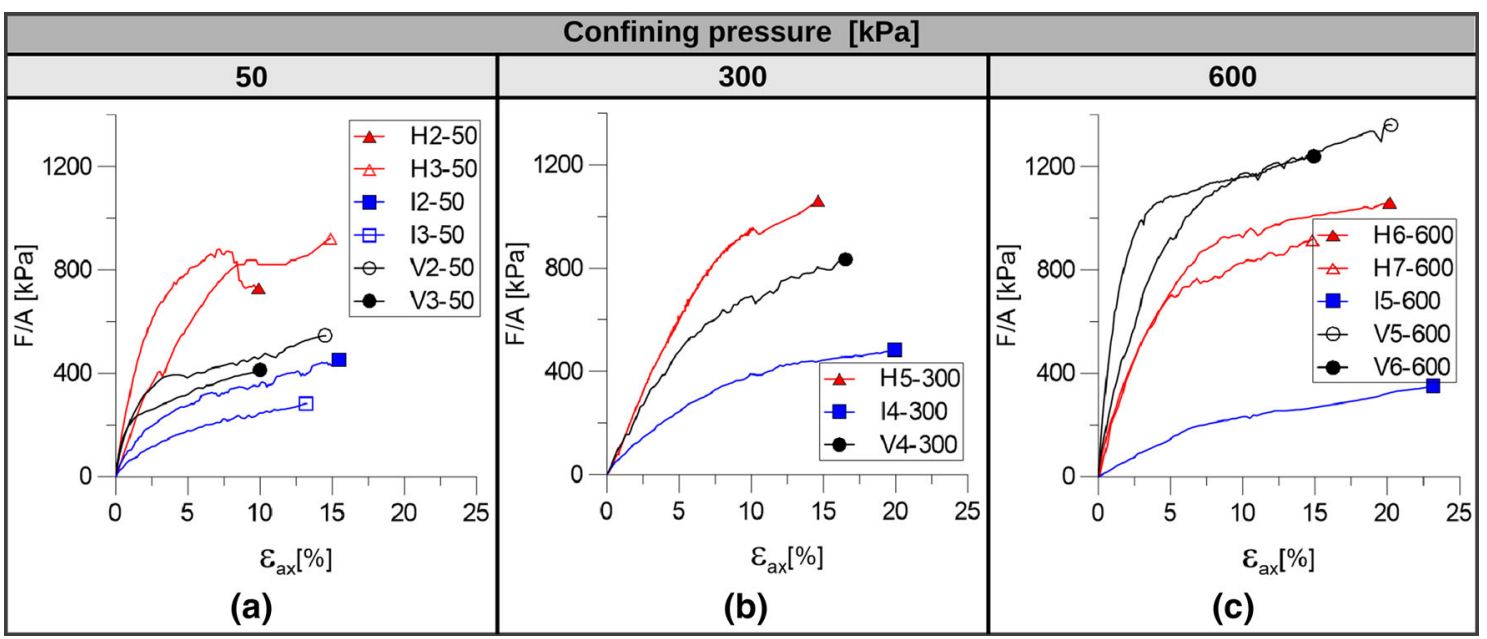

Fig. 14 Effect of initial fissure inclination and confining pressure

specimens with horizontal fissures exhibits a stress peak. This is consistent with the circumstance, given by absent or low confinement, that these tests may be considered similar to undrained shear tests carried out at a state comparable with the initial one. As such, the scaly clay is in an overconsolidated state, consistent with a dry response to shear. When increasing the confining pressure (from 50 to 300 and $600 \mathrm{kPa}$ ), their response changes from brittle to ductile and strain hardening is observed. This is not the case for the stress-state response of specimens with medium inclined and vertical fissures, which is always characterised by strain hardening. Moreover, specimens with vertical fissures showed a significant increase in shear strength, while the response of the specimens with medium-inclined fissures was essentially independent on the confining pressure. As far as the initial stiffness is concerned, it appears that the response of specimens with medium-inclined fissures is the softest, whatever the confining pressure. The specimens with horizontal fissures do not seem to be sensitive to the confining pressure, while in the case of vertical fissures, the stiffness significantly increased at the highest confinement.

All these results are consistent with the observation that when fissures are not horizontal, provided the confinement is relatively low, the deformation process consists of the activation of pre-existing fissures between near-rigid portions of the specimen from the very beginning of loading and a ductile global response is recorded. When the confining pressure becomes sufficiently high, the initial fissures tend to close, and therefore, their role in the deformation process is reduced. The global stress-strain response of the specimens, whatever their fissuring orientation, seems to become consistent with traditional soil mechanics.

\section{Discussion of the results}

Figure 15 summarises the results by combining them in a confining pressure-fissure inclination matrix. Each cell of the matrix corresponds to one representative test and shows the relevant stress-strain curve with the strain fields at the beginning of the test and at the onset of localisation, as well as a sketch of the failure pattern at the end of the test. The rows of the matrix show the results as a function of the four levels of confining pressure $(0,50,300$, and $600 \mathrm{kPa})$, while the columns refer to the three different fissure inclinations to the horizontal $\left(0^{\circ}, 45^{\circ}\right.$, and $\left.90^{\circ}\right)$.

All cells with a light blue background refer to those tests in which the deformation process, including strain localisation, was found to be essentially the same as that observed in unfissured clays. In particular, for all these tests, the deformation process was initially quite homogeneous, with the onset of strain localisation roughly corresponding to the point where the global stress-strain curve departs from linearity. Localised deformation develops further past the stress peak, eventually leading to a mechanism of relative sliding of almost rigid blocks. Note that, in all specimens with horizontal fissures, the observed patterns of localisation show higher complexity, e.g. $\mathrm{x}$-shaped failure mechanisms, as compared to those observed for medium inclined and vertical fissures.

Scaly clay specimens characterised by medium-inclined and vertical fissures and tested at zero or $50 \mathrm{kPa}$ confining pressure behave differently. (The corresponding cells in the matrix have a light red background.) In these tests, the deformation process essentially consisted of sliding between nearly rigid portions of the specimen already from the early stages of loading. The sliding was accompanied and followed by compaction (fissure closing) and dilation (fissure opening). Axial splitting along pre-existing fissures was observed when specimens with vertical fissures were 


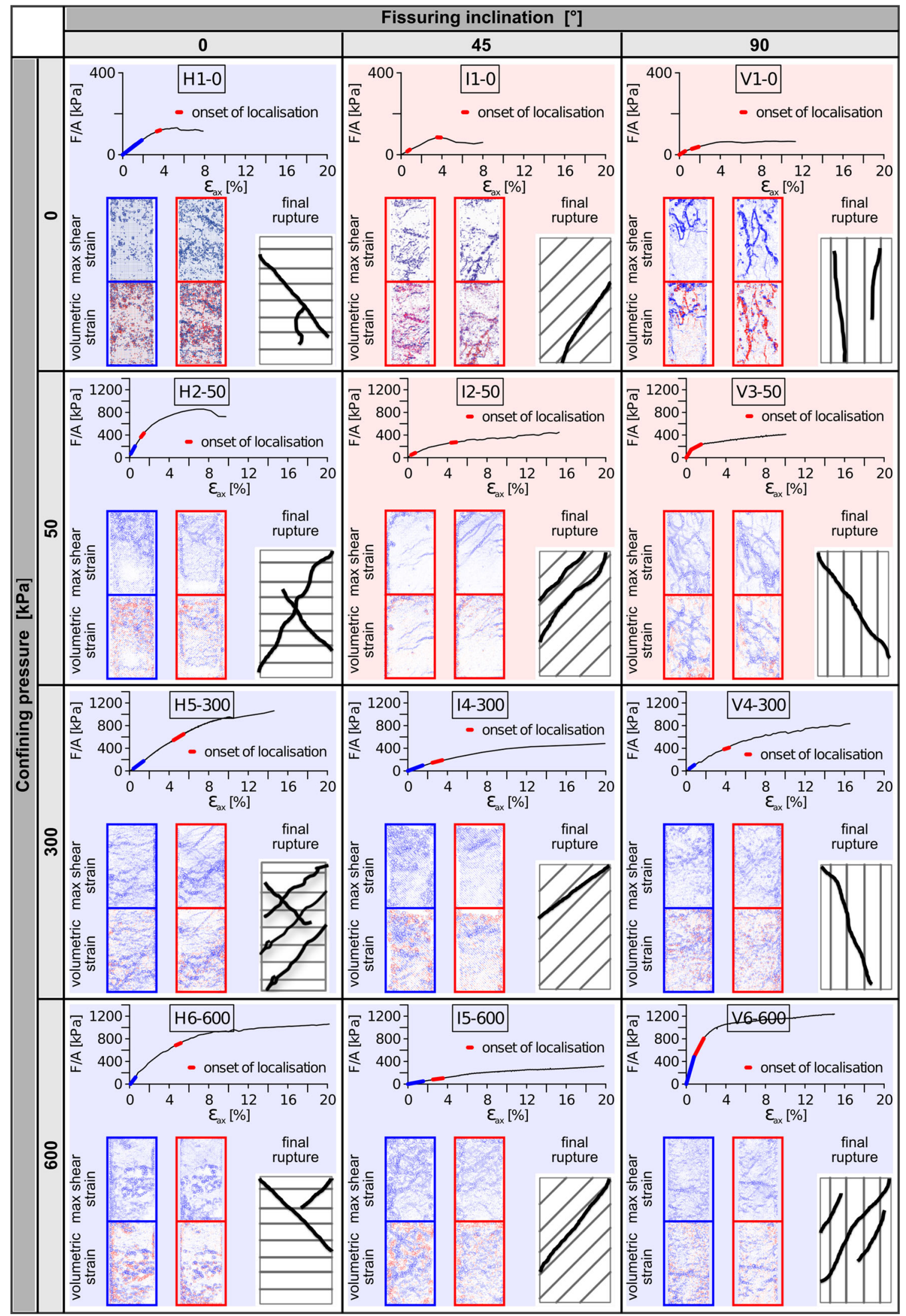

Fig. 15 Confining pressure-fissures inclination matrix 


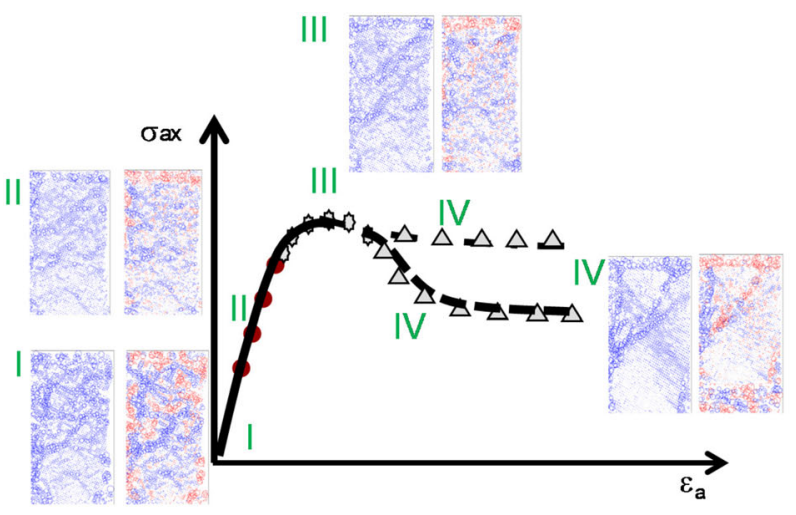

(a) Continuum behaviour: matrix combinations $\mathrm{H}-0 \mathrm{H}-50 \mathrm{H}-300 \mathrm{H}-600 \mathrm{I}-300 \mathrm{I}-600 \mathrm{~V}-300 \mathrm{~V}-600$

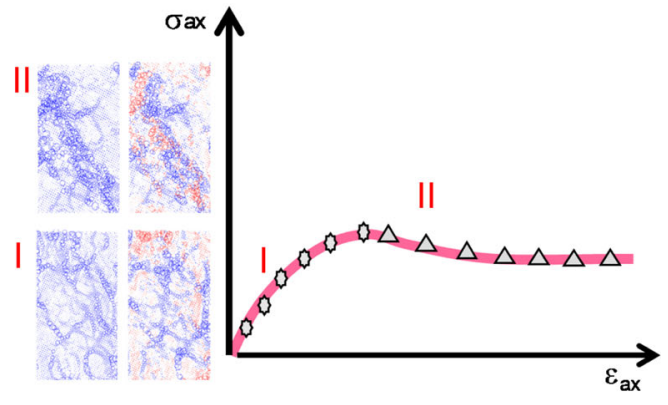

(b) Discrete behaviour: matrix combinations I-0 I-50 V-0 V-50

Fig. 16 Sketch of main findings from our previous studies and this study on intensely fissured clay from Santa Croce di Magliano. The sketch reports global stress-strain behaviour and examples of DIC-derived strain fields (deviatoric on the left and volumetric on the right) for a continuum behaviour and $\mathbf{b}$ discrete behaviour

loaded at zero confining pressure, whereas for medium fissures inclination, the deformation localised very early in the test and consisted essentially of the activation of the fissures, which are all potential failure surfaces.

The matrix in Fig. 15 confirms the sketch previously shown in Fig. 1 and extends it to include the important effect of confining pressure. In fact, this figure summarises the key conclusions of this work relatively to the effects of fissure orientation and confining pressure on the global mechanical response to deviatoric loading (in plane strain) and the patterns of strain localisation eventually leading to failure. With this, the sketch of Fig. 1 can be extended by the one of Fig. 16, where two types of behaviour are identified:

Continuum behaviour (Fig. 16a): for horizontal (whatever the confining pressure), medium-inclined, and vertical fissures at $300-600 \mathrm{kPa}$ confining pressure, the deformation process is similar to that of intact (unfissured) clays (cells with light blue background in Fig. 15); Discrete behaviour (Fig. 16b): for medium-inclined and vertical fissures and $0-50 \mathrm{kPa}$ confining pressure, multiple pre-existing fissures are activated since the early stages of loading and the deformation process is governed by the fissures, with nearly rigid portions of the specimen moving relative to each other (cells with light red background in Fig. 15). No peak is observed in the global stress-strain response for discrete behaviour.

\section{Conclusions and perspectives}

The coupled effects of confining pressure and fissure inclination on the global behaviour and strain localisation phenomena of the intensely fissured scaly clay from Santa
Croce di Magliano have been investigated by means of a number of plane strain compression tests. Specimens having vertical, medium-inclined and horizontal fissure inclinations were tested at three different confining pressures $(50,300$ and $600 \mathrm{kPa})$. The results were compared with previous tests carried out on the same material, but without confinement [20]. The standard, global stress-strain response was complemented by the measurement of strain fields through 2D digital image correlation. The incremental strain fields allowed the deformation processes to be followed throughout each test, providing both spatial and temporal information about strain evolution in relation to the global stress-strain response.

The key conclusions from this work are summarised in the sketch in Fig. 16, where two types of behaviour have been identified: a continuum-type behaviour, where the deformation process is similar to that of intact (unfissured) clays, and a discrete-type behaviour, where multiple preexisting fissures are activated since the early stages of loading and the deformation process is governed by the fissures. The continuum-type behaviour occurs for horizontal (whatever the confining pressure), medium-inclined and vertical fissures at $300-600 \mathrm{kPa}$ confining pressure, while the discrete-type is observed for medium-inclined and vertical fissures, at $0-50 \mathrm{kPa}$ confining pressure.

Although these results have been obtained on a specific natural material, the scaly clay from Santa Croce di Magliano, it is the authors' contention that most of the conclusions are applicable to other fissured materials as well-in this sense, the matrix presented in Fig. 15 and the sketch of Fig. 16 suggest a more general framework for understanding the complex mechanical interplay between pre-existing fissures and mean stress level. Moreover, modelling of the fissured soil behaviour should take into 
account the coupling between fissure orientation and confinement. These results can, in fact, be used to support modelling strategies switching from continuum-type to discrete-type approaches.

Further experiments in this study should include the control of saturation and drainage, which are both expected to influence the (localised) deformation processes. This would also enable quantification of the combined effect of fissure orientation and confining pressure on the effective strength parameters of scaly clays. Another possible perspective is the investigation of loading conditions different from plane strain, e.g. triaxial compression and extension. In this respect, triaxial compression tests are ongoing on scaly clay specimens with the aim to explore the influence of these effects on the global effective strength of the clay. The analysis of the local behaviour, of course, will require 3D imaging, e.g. by means of x-ray tomography; see, e.g. $[6,9]$ for recent applications of $\mathrm{x}$-ray tomography and digital volume correlation to stiff clays.

Acknowledgements The authors gratefully acknowledge M.Sc. students Francesco Massaro and Alessandra Castellano for their support in the experimental work. Some of the results were obtained during their research internships at Lund University. Laboratoire 3SR is part of the LabEx Tec21 (Investissements d'Avenir-Grant Agreement ${ }^{\circ}$ ANR-11-LABX-0030).

Funding Open access funding provided by Lund University. Not applicable.

Availability of data and materials Not applicable.

Code availability The software used for Digital Image Correlation, TomoWarp2, can be found at https://github.com/ElsevierSoftwareX/ SOFTX-D-17-00061.

\section{Declaration}

Conflict of interest Not applicable.

Open Access This article is licensed under a Creative Commons Attribution 4.0 International License, which permits use, sharing, adaptation, distribution and reproduction in any medium or format, as long as you give appropriate credit to the original author(s) and the source, provide a link to the Creative Commons licence, and indicate if changes were made. The images or other third party material in this article are included in the article's Creative Commons licence, unless indicated otherwise in a credit line to the material. If material is not included in the article's Creative Commons licence and your intended use is not permitted by statutory regulation or exceeds the permitted use, you will need to obtain permission directly from the copyright holder. To view a copy of this licence, visit http://creativecommons. org/licenses/by/4.0/.

\section{References}

1. A. D2487-17e1 (2017) Standard practice for classification of soils for engineering purposes (unified soil classification system).
Technical report, ASTM International, West Conshohocken, PA. www.astm.org

2. A. D422-63(2007)e2 (2007) Standard test method for particlesize analysis of soils (withdrawn 2016). Technical report, ASTM International, West Conshohocken, PA. www.astm.org

3. A. D4318-17e1 (2017) Standard test methods for liquid limit, plastic limit, and plasticity index of soils. ASTM international. Technical report, ASTM International, West Conshohocken, PA. www.astm.org

4. Athanasopoulos SD (2019) Multiscale granular mechanics: a neutron diffraction based experimental approach. Ph.D. thesis, Lund University

5. Bishop A (1967) Progressive failure-with special reference to the mechanism causing it. In: Proc. Geotech. Conf., Oslo, vol 2, pp $142-150$

6. Bésuelle P, Ando E (2014) Characterization of the mechanisms of deformation at the small scale in a clay rock by in-situ X-ray micro tomography. In: International symposium on geomechanics from micro to macro (2014)

7. Chandler R (1973) Study of structural discontinuities in stiff clays using a polarising microscope. In: Proceedings international symposium on soil structure (Gothenburg, 1973), pp 78-85

8. Cotecchia F, Vitone C, Santaloia F, Pedone G, Bottiglieri O (2015) Slope instability processes in intensely fissured clays: case histories in the Southern Apennines. Landslides 12(5):877

9. Lenoir N, Bornert M, Desrues J, Bésuelle P, Viggiani G (2007) Volumetric digital image correlation applied to X-ray microtomography images from triaxial compression tests on argillaceous rock. Strain 43(3):193

10. Lo K (1970) The operational strength of fissured clays. Geotechnique 20(1):57

11. Marsland A (1971) The shear strength of stiff fissured clays. In: University C (ed) Proceeding of the roscoe memorial symposium, pp 59-68

12. Nardelli V, Coop M, Vitone C, Chen S (2016) The inter-scale behaviour of two natural scaly clays. Géotech Lett 6(3):205

13. Tudisco E, Andò E, Cailletaud R, Hall SA (2017) TomoWarp2: a local digital volume correlation code. SoftwareX 6:267

14. Tudisco E, Vitone C, Mondello C, Viggiani G, Hall SA, Cotecchia F, Castellano A, Massaro F (2019) Influence of fissure inclination and confining pressure on the local behaviour of natural clays. In: E3S web of conferences, vol 92 (EDP Sciences, 2019), p 03004

15. Vitone C, Cotecchia F (2011) The influence of intense fissuring on the mechanical behaviour of clays. Géotechnique 61(12):1003

16. Vitone C, Cotecchia F, Desrues J, Viggiani G (2009) An approach to the interpretation of the mechanical behaviour of intensely fissured clays. Soils found 49(3):355

17. Vitone C, Cotecchia F, Federico A, Viggiani G (2018) On the geomechanical characterisation of complexities in clays: experimental studies. Ital Geotech J -Rivista Italiana Di Geotecnica $52(2): 7$

18. Vitone C, Cotecchia F, Viggiani G, Hall S (2013) Strain fields and mechanical response of a highly to medium fissured bentonite clay. Int J Numer Anal Methods Geomech 37(11):1510

19. Vitone C, Guglielmi S, Pedone G, Cotecchia F (2019) Effects of micro-to meso-features on the permeability of fissured clays. Géotech Lett 9(4):369

20. Vitone C, Viggiani G, Cotecchia F, Hall S (2013) Localized deformation in intensely fissured clays studied by $2 \mathrm{D}$ digital image correlation. Acta Geotech 8(3):247

Publisher's Note Springer Nature remains neutral with regard to jurisdictional claims in published maps and institutional affiliations. 